\title{
Novedades para la Flora de la Argentina
}

\author{
JUAN J. CANTERO ${ }^{1,2, *}$, GLORIA E. BARBOZA ${ }^{2,3}$, FRANCO E. CHIARINI ${ }^{2}$, ROCIO DEANNA ${ }^{2,3}$, \\ L. ARIZA ESPINAR ${ }^{2}$, MELISA A. GIORGIS ${ }^{2}$, CESAR O. NÚÑEZ ${ }^{1}$ y GABRIEL BERNARDELLO²
}

\begin{abstract}
Resumen: Con motivo de estar preparando la Flora de Córdoba, han surgido numerosas novedades para la flora argentina, a raíz de haberse intensificado los viajes de campo y la revisión de las colecciones de los principales herbarios del país. En este trabajo se dan a conocer tres nuevas citas para la flora nativa y 17 para la flora introducida de la Argentina (especies casuales y naturalizadas). Se describen e ilustran los nuevos registros y se realiza una lectotipificación. Además, se documenta formalmente por primera vez la presencia de 10 especies introducidas.
\end{abstract}

Palabras clave: Nuevos registros, flora introducida, flora nativa, Argentina, lectotipificación.

\begin{abstract}
Summary: Novelties for the Flora of Argentina. On the occasion of preparing the Flora of Cordoba, new records for the Argentinean flora have been registered as a result of intensive field trips and the revision of the main herbaria collections of the country. In this paper, three new records for the native flora and 17 for the introduced flora (casual aliens and naturalized species) of Argentina are presented. Descriptions, illustrations and a lectotypification are done. Furthermore, the presence of 10 introduced species is formally documented for the first time.
\end{abstract}

Key words: New records, introduced flora, native flora, Argentina, lectotypification.

\section{INTRODUCCIÓN}

A raíz de estar preparando la Flora de Córdoba, se han realizado diferentes campañas de colección en diversos sitios de esta provincia que aún restaban monitorearse, a la par que se ha intensificado la revisión de las colecciones de herbario. Esto dio lugar a encontrar nuevos registros para la flora nativa e introducida de la Argentina, con especies que crecen en Córdoba, y una en Misiones. Asimismo, en los últimos años han aparecido algunos trabajos florísticos y agronómicos (Balabusic et al., 1994; Cozzo, 1994; Troiani \&

${ }^{1}$ Departamento Biología Agrícola, Facultad de Agronomía y Veterinaria, UNRC, Ruta Nac. 36, Km. 601, 5804 Río Cuarto, Córdoba.

2 Departamento Biología Agrícola, Facultad de Agronomía y Veterinaria, UNRC, Ruta Nac. 36, Km. 601, 5804 Río Cuarto, Córdoba.

${ }^{3}$ Facultad de Ciencias Químicas, UNC. Haya de la Torre y M. Allende s.n., Córdoba.

*Autor para correspondencia: juanjocantero@gmail.com
Steibel, 2008; Zalba et al., 2008; Cuevas \& Zalba, 2009; Delucchi et al., 2011; Giorgis et al., 2011a, b; Nievas \& Moglia, 2013; Giorgis \& Tecco, 2014; Leuenberger \& Arroyo-Leuenberger, 2014) que citan, sin documentar con ejemplares de herbario, especies introducidas para nuestro país. El objetivo del presente artículo es dar a conocer los nuevos registros y documentar formalmente la presencia de las especies introducidas. Se aportan datos taxonómicos y de distribución de estos taxones y se da a conocer el estatus actual de sus poblaciones.

\section{Materiales y Métodos}

Se realizaron viajes de campo en la provincia de Córdoba, particularmente a los paisajes serranos y periserranos y, además, a los ambientes riparios $\mathrm{y}$ otros con perturbaciones antrópicas pasadas o recientes (ruderales). Se consultaron también los herbarios CORD, CTES, LP, LIL, RIOC y SI.

Los nuevos registros se presentan en dos apartados: I. Nuevas citas para la flora nativa y II. 
Nuevas citas para la flora introducida. En cada caso, las familias están ordenadas alfabéticamente al igual que los géneros y especies dentro de cada familia. Se describen las especies nativas e introducidas, las primeras se acompañan con ilustraciones mientras que para las segundas se presentan fotografías tomadas en su hábitat.

Para la identificación de las especies se ha recurrido a bibliografía específica que se cita para cada especie, y en casi todos los casos, se han consultado los tipos nomenclaturales a través de JSTOR (http://plants.jstor.org) o por la provisión de imágenes digitales de los respectivos herbarios donde ellos están depositados (B-W, LE, M). El nombre actual de las especies ha sido corroborado en Plant List (www.theplantlist.org) y, en algunos casos, se ha seguido el criterio de aceptar las novedades provenientes de las publicaciones más recientes. Para las especies introducidas, se tuvieron en cuenta las categorías propuestas por Richardson et al. (2011) quienes reconocen a lo largo del continuum del proceso de la invasión a las especies casuales, naturalizadas e invasoras.

En el apartado III se documenta, con material de herbario de alguno de los autores de este trabajo, la presencia de especies introducidas ya citadas para Argentina por otros autores.

\section{Resultados}

\section{Nuevas citas para la flora nativa}

\section{Alismataceae}

Echinodorus scaber Rataj, Folia Geobot. \& Phytotax. 4: 438. 1969. Tipo. BRITISH GUIANA: Mounth of Canje River, XII-1887, Jenman 4310 (Holotypus K 000098302!). Fig. 1.

Echinodorus macrophyllus subsp. scaber (Rataj) R.R. Haynes \& Holm-Niels., Brittonia 38: 331. 1986.

Hierbas perennes de 0,5-2 m de alt., glabrescentes; raíces con gran cantidad de pequeños tubérculos de 2-5,5 x 1-2,5 mm; rizomas cortos y erectos. Hojas emergentes, verde-castañas, de 9-41 x 4,9-26 (40) cm, ovadas a ovado-lanceoladas, sin puntos pelúcidos, de base cordada o truncada, pecíolos muy estriados, más largos que la lámina, de 17-41 cm long., con pelos estrellados sobre todo en su ápice. Inflorescencia paniculada o rara vez racemosa, ca. 50 (-200) cm long., verticilos 7-14, con 8-20 flores cada uno, raquis multi-costado, con pubescencia de pelos estrellados; brácteas lanceoladas de 0,3-2,5 $\mathrm{cm} \times 2,5-4 \mathrm{~mm}$, pedicelos de 0,4-3,5 cm long. Flores de 11-20 mm lat.; sépalos erectos, con unas 9 carenas; pétalos de 4-5 x 3-3,5 $\mathrm{mm}$, reflexos; estambres 13-18, anteras versátiles de 0,7-1 mm long., filamentos ca. $2 \mathrm{~mm}$ long.; carpelos numerosos. Aquenios obovoides, de 2,3-2,8 x 1-1,5 $\mathrm{mm}$, con un ala estrecha, nervios emergentes y $1-5$ glándulas linear-elípticas entre las costillas; rostro lateral erecto, de 0,5-1 $\mathrm{mm}$ long.

Distribución y hábitat. Nativa desde Centro América hasta Bolivia, Paraguay y Brasil (Haynes \& Holm-Nielsen, 1994; Lehtonen, 2008) y la Argentina donde se la cita sólo para la provincia de Córdoba y Corrientes. Crece en sitios periféricos a lagunas, con inundación temporaria.

Obs. La lámina de Flora Argentina (http://www. floraargentina.edu.ar/) citada como Echinodorus grandiflorus (Cham. \& Schltdl.) Micheli corresponde a este taxón.

Material estudiado. ARGENTINA. Prov. Córdoba. Dpto. Río Primero, Cerro Solo (en el Puesto de Crocci), a la vera del terraplén que une Villa Fontana con Las Saladas, 24-IV-1974, A. T. Hunziker 22522 (CORD). Laguna Dulce, cerca de Las Saladas (Mar Chiquita), F. Kurtz 4757, 7-III-1887 (CORD). Dpto. San Justo, camino a Miramar, unos $6 \mathrm{~km}$ al norte de Villa Concepción del Tío, A. T. Hunziker 13370, 2-II-1957 (CORD). Dpto. Totoral, entre Estancia Noriega y Los Mistoles, 28-II-1887, F. Kurtz 4488 (CORD). Prov. Corrientes. Dpto. Santo Tomé, Ruta 40 y Arroyo Chimiray, 12-XI-1974, A. Schinini \& Carnevali 10316 (CTES).

\section{Crassulaceae}

Crassula venezuelensis (Steyerm.) M.Bywater \& Wickens, Kew Bull. 39 (4): 710. 1984. Fig. 2, 4 A, B.

Basónimo: Tillaea venezuelensis Steyerm., Fieldiana, Bot. 28: 914. 1957. Tipo. VENEZUELA: Est. Mérida: Near upper limit of páramo, around small lake, between Chachopo and Los Apartaderos, near El Aguila, 3930 m, 15-IV-1944, 


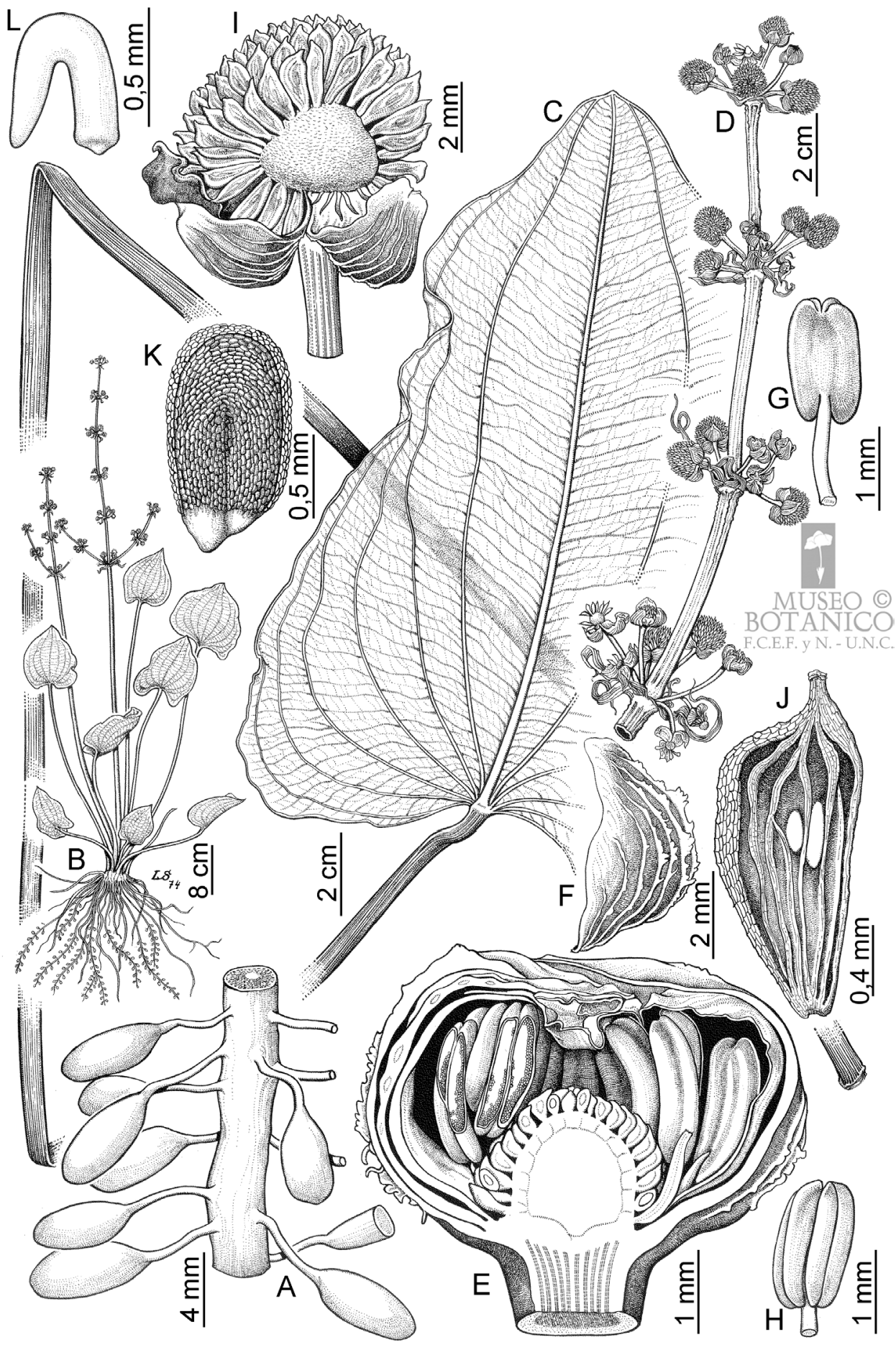

Fig. 1. Echinodorus scaber. A: Sector de raíz con engrosamientos tuberiformes. B: Planta. C: Hoja. D: Ápice de inflorescencia. E: Botón floral, en corte longitudinal. F: Vista dorsal de un sector de uno de los sépalos para mostrar las costillas longitudinales. G-H: Antera, en vista dorsal y ventral, respectivamente. I: Vista lateral de un fruto maduro. J: Aquenio. K: Semilla. L: Embrión. 
Steyermark 55906 (Holotypus F0055006!; isotypi: G 00305814!, K 000486219!, MO-247764!, NY 00007138 !, US, VEN 45134!).

Hierbas acuáticas, sumergidas, decumbentes a erectas, hasta ca. $10 \mathrm{~cm}$ long., enraizantes en los nudos. Hojas opuestas, decusadas, formando una vaina en el nudo, angosto-lanceoladas, submucronadas, enervias, de 3-5,5 x 1-1,2 mm, inclinadas o patentes respecto al eje. Flores solitarias, tetrámeras, perfectas, actinomorfas, de
1,2-2 mm x 1-1,9 mm, subsésiles o pediceladas; pedicelos hasta ca. $15 \mathrm{~mm}$ long.; sépalos suculentos, triangular-ovados, ca. 0,75 mm long.; pétalos membranosos, más largos que los sépalos, ca. 1,75 mm long.; escamas filamentosas, ca. 0,6 mm long.; carpelos obovoides, con 6-8 óvulos, estigma sésil. Folículos pluriseminados, pericarpo tenue; semillas oblongas, de 0,54-0,63 x 0,2$0,25 \mathrm{~mm}$, castañas, longitudinalmente estriadas, células del episperma no papilosas, con paredes onduladas.

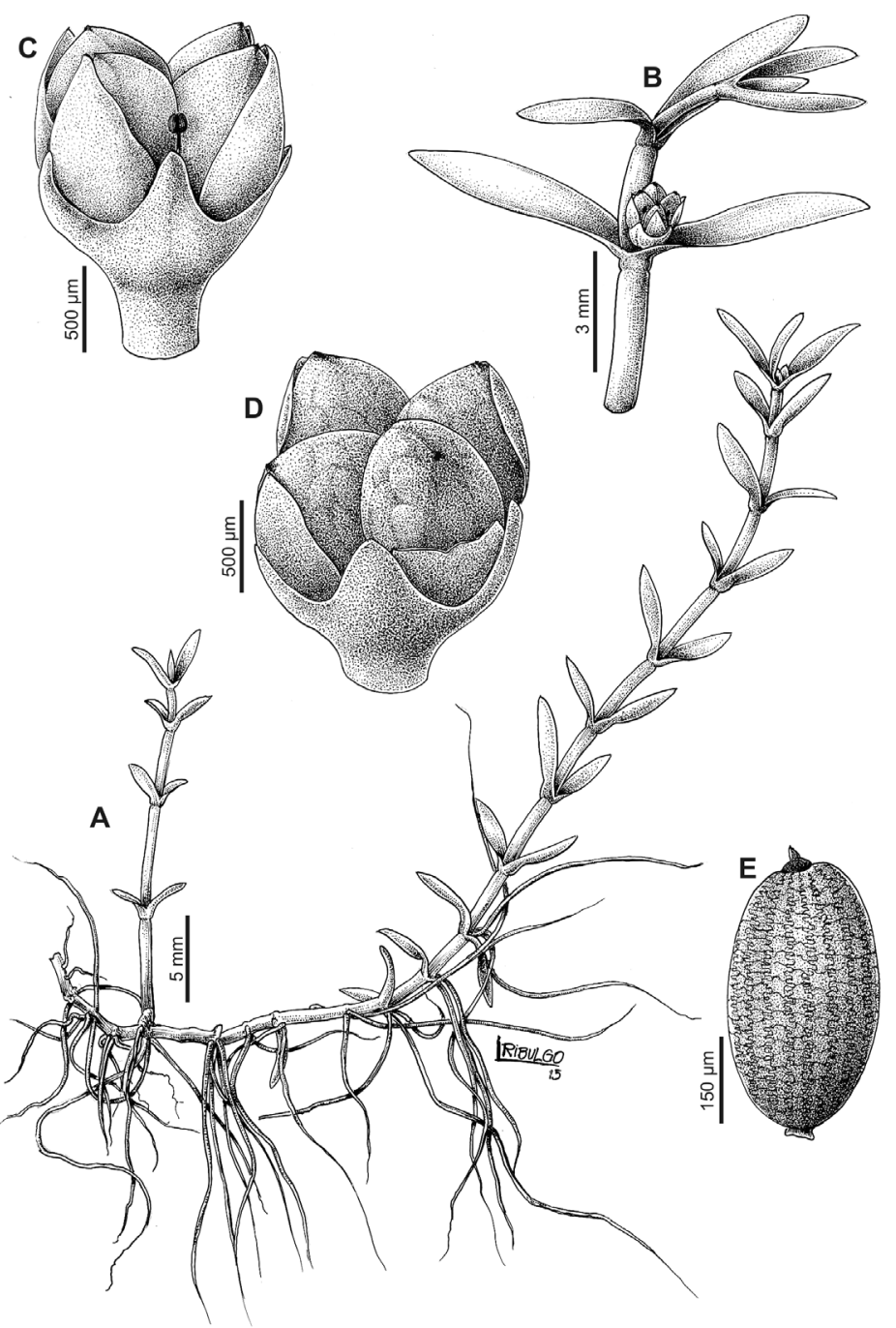

Fig. 2. Crassula venezuelensis. A: Planta. B: Ápice de rama con flor axilar. C: Flor. D: Fruto. E: Semilla. 


\section{J. J. Cantero et al. - Novedades para la flora de la Argentina}

Distribución y hábitat. Desde Venezuela hasta Sudamérica austral: Colombia, Ecuador, Perú, Bolivia y probablemente Chile (Bywater \& Wickens, 1984). En la Argentina, se citan aquí dos poblaciones localizadas en pequeños arroyos serranos cordobeses de aguas muy frías, en el Valle de Punilla y la Sierra de Comechingones, donde crece arraigada en el fondo del cauce.

Material estudiado. ARGENTINA. Prov. Córdoba. Dpto. Cruz del Eje, Sierra Grande (falda E), alrededores del Arroyo Aguas Turbias, entre Tanti y Río Yuspe (RP 28, ex RN 20), 1750 m, 11-III-1986, R. Subils et al. 3918 (CORD). Dpto. Río Cuarto, Las Albahacas, arroyo Morteritos, 32 $2^{\circ} 52^{\prime} 55^{\prime}$ 'S, 64 $50^{\circ} 46^{\prime \prime} \mathrm{W}, 779 \mathrm{~m}$, J. J. Cantero 7151 (19-VIII-2015) \& 7162 (8-X-2015) (CORD).

\section{Rosaceae}

Rubus erythrocladus Mart. ex Hook.f., Fl. Bras. [Martius]14 (2): 62. 1867. Tipo.

[BRASIL] Est. Minas Gerais: Habitat in sepibus prope Capaó, ubi Tapazii inveniuntur, C.F.P. Martius 853 (Lectotypus aquí designado: $\mathrm{M}$ 0214178!). Fig. 3.

Arbustos hasta ca. $2 \mathrm{~m}$ alt. Tallos rojizos, decumbentes, los adultos estriados, ca. $11 \mathrm{~mm}$ diám., densamente cubiertos por aguijones rojizos, gruesos, patentes, hasta ca. $7 \mathrm{~mm}$ long. y con largas setas también rojizas terminadas en una glándula; tallos más jóvenes y floríferos con aguijones menos robustos, muy punzantes, curvados y retrorsos. Hojas coriáceas, las inferiores 5-folioladas, las superiores 3-folioladas, pecíolos de (2) 3-6 cm long. y peciólulos de 1,2-2,2 cm long., ambos con aguijones curvos y retrorsos y setas glandulosas; en hojas 3-folioladas, folíolos laterales a veces subsésiles; folíolos levemente discoloros, elípticos o angostamente-elípticos, raro ovados, base redondeada o cordada, ápice agudo a acuminado, margen agudamente aserrado, epifilo brillante, castaño-rojizo, glabro o apenas glabrescente, hipofilo opaco, castaño-rojizo o verdoso, glabro, nervio principal con pequeños aguijones retrorsos dispersos; éste y los nervios laterales con largos pelos no glandulares antrorsos, blanquecinos, tenues; folíolo terminal de 7-11 x 2,2-3,9 cm; los laterales de 5-7,5 x 2,2-3,4 $\mathrm{cm}$; estípulas 2 , rojizas, soldadas parcialmente al pecíolo, 10-12 $\mathrm{mm}$, con pelos no glandulares brillantes. Inflorescencia terminal tirsoidea, con más de 10 flores; pedúnculos, raquis y pedicelos con abundante pilosidad no glandular blanquecina, con pequeños pelos glandulares rojizos dispersos y con numerosas y largas setas glandulosas y aguijones rectos y retrorsos; brácteas y bractéolas 1-2, enteras, triangulares, con pubescencia blanquecina. Flores perfectas, ca. 12-14 mm diám.; sépalos reflexos, persistentes, anchamente ovados y con un breve mucrón, superficie interna cóncava, de 6-7 x ca. 3,2 mm, densamente cubiertos por cortos pelos eglandulares por dentro y además con algunos pelos glandulares por fuera; pétalos blancos, obovados, ápice redondeado, borde crenado, de $8-9$ x ca. 6 $\mathrm{mm}$; estambres numerosos, filamentos de $3-4 \mathrm{~mm}$ long.; carpelos casi tan largos como los estambres o apenas más cortos, ovario obovoide, de $1,25 \mathrm{x}$ $0,7 \mathrm{~mm}$, pubescente en su base, estilo de $1,5 \mathrm{~mm}$ long., estigma bífido. Fruto subgloboso a elipsoidal, ca. 1,2-1,4 x $1 \mathrm{~cm}$; drupéolas 20-40, glabras, de color castaño claro en el centro y más oscuro hacia los bordes, con superficie reticulado-foveolada, algunas con estilo persistente.

Distribución y hábitat. Nativa del sur y sudeste de Brasil (desde Rio Grande do Sul hasta Mina Gerais y Rio de Janeiro), donde crece en el Cerrado y la Mata Atlántica (Simão-Bianchini, 2015). En la Argentina, fue coleccionada en la provincia de Misiones, sólo en dos oportunidades.

Obs. Se analizaron los tres síntipos citados en el protólogo: Martius 853 (M!), Gardner 4546 (K!) y Pohl s.n. (M!); se designa como lectotipo el ejemplar de Martius por estar constituido por dos ramas floríferas. Los dos restantes son especímenes en fruto.

Especie muy característica por el color rojizo de los tallos, los aguijones y las largas setas glandulíferas, y por sus hojas coriáceas y glabras. En Brasil, los frutos son comestibles, consumidos por el hombre, pájaros y otros animales (Reitz, 1996).

Material estudiado. ARGENTINA. Prov. Misiones. Dpto. Gral. M. Belgrano, entre San Antonio y Bernardo de Yrigoyen, 30-X-1960, L. Ariza Espinar 1180 (CORD). Ruta 101, cerca de San Antonio, 30-X1960, A. T. Hunziker et al. 15475 (CORD). 
Bol. Soc. Argent. Bot. 51 (1) 2016

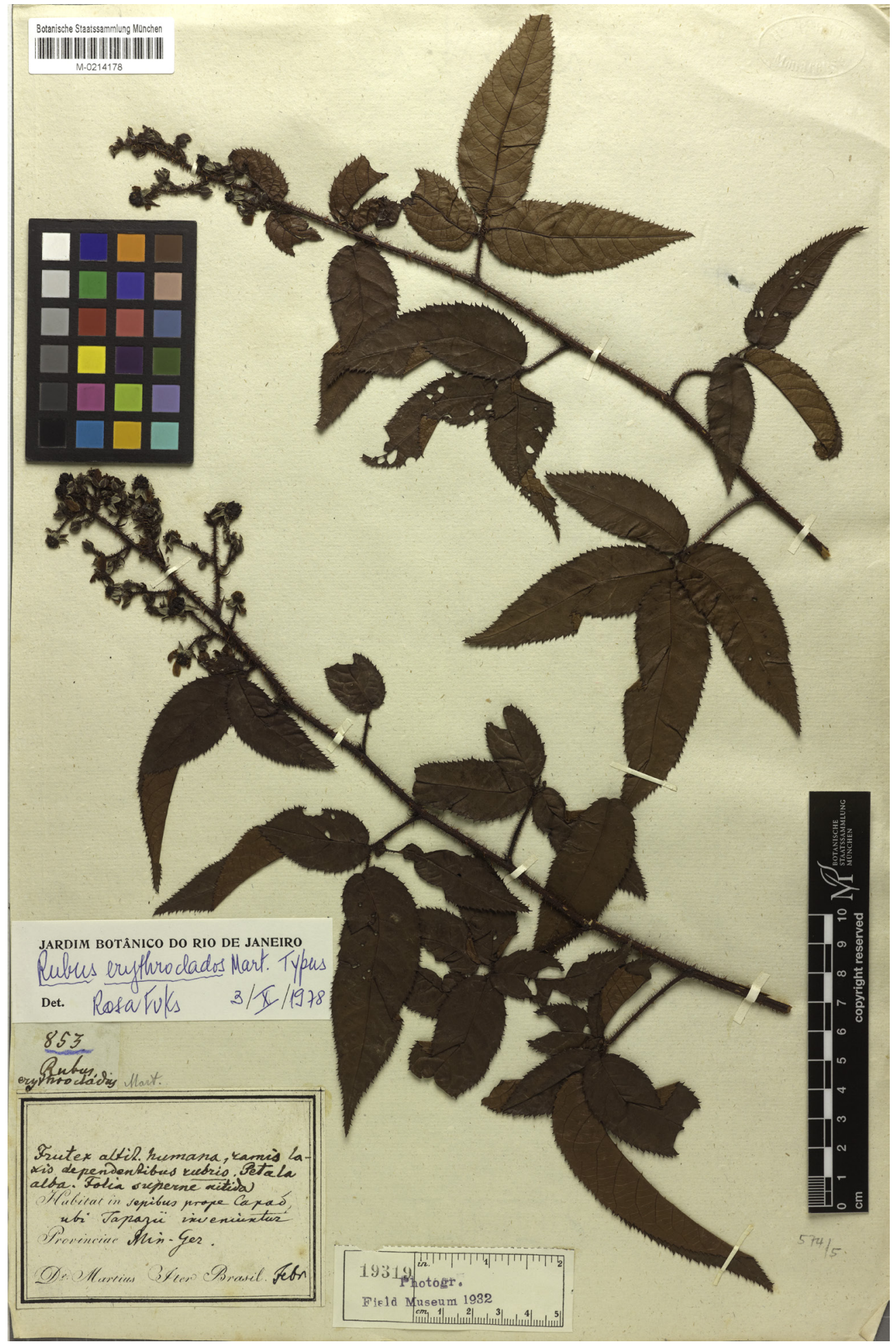

Fig. 3. Lectotipo de Rubus erythrocladus. Reproducción autorizada por Botanische Staatssammlung München (M). 


\section{J. J. Cantero et al. - Novedades para la flora de la Argentina}

BRASIL. Minas Gerais, near Itambé, VIII-1840, C. Gardner 4546 (K 000424880). Villa Ricca, 1839, J. B. Pohl s.n. (M 0214179). Rio Grande do Sul, Montenegro, L. Campestre, 21-IX-1949, A. Sehnem 3875 (SI). Santa Catarina, Stranch im Walde bei Minas, IV-1889, E. H. Ule 1119 (CORD).

\section{Nuevas citas para la flora introducida}

En los últimos años en nuestro país se ha generado un interés creciente por las especies de plantas exóticas fuera de su área de distribución natural por causas antrópicas, tanto como potenciales especies invasoras (Zalba et al., 2000; Zalba \& Villamil, 2002; Zalba \& Ziller, 2007; Natale et al., 2008; Cuevas \& Zalba, 2009, 2010, 2013; Giorgis et al., 2011 a, b; Busso et al., 2013; Morichetti et al., 2013; Fonseca et al., 2013; Torresin et al., 2013; Ferreras et al., 2014) como también por su posible naturalización e integración a la flora del país, y en especial, las especies ornamentales escapadas de cultivo (Delucchi, 1996, 1999, 2003; Hurrell \& Delucchi, 2007 a, b; Hurrell et al., 2009, 2010, 2012; Arana \& Oggero, 2009; Delucchi \& Hurrell, 2011; Arana et al., 2012). En esta sección se presentan nuevos integrantes de nuestra flora introducida que se han localizado y coleccionado en áreas por fuera de los sitios cultivados: bordes de montes forestales, terrenos aledaños a viviendas abandonadas en las montañas, baldíos y basurales con restos de acarreos de tierra, escombros y desechos de jardines tanto en pueblos como en ciudades, y bordes de caminos y vías férreas en el espacio periurbano y en el campo.

\section{Asparagaceae}

Beschorneria yuccoides K.Koch, Wochenschr. Gärtnerei Pflanzenk. 2: 337. 1859. Tipo: MEXICO. Hidalgo: Parque Nacional El Chico, $3 \mathrm{~km}$ al NW de Pueblo Nuevo, 22-IV-1984, A. García-Mendoza \& Mérida 1418 (Neotypus MEXU; isoneotypi K000524839!, UC, US01049772!, designado por García-Mendoza, Monocot. Mexic. 1: 30. 1993). Fig. 4 C-E.

Hierbas acaules, rizomatosas, ca. 1,5 m alt. Raíces fibrosas o carnosas. Hojas sésiles, dispuestas en una roseta basal, erectas, persistentes, de 30-90 x 3-10 cm, linear-lanceoladas, ápice acuminado, márgenes finamente denticulados, grisverdosas a verdes, glaucas, cara superior glabra, cara inferior escabrosa. Inflorescencias de 1-1,8 $\mathrm{m}$ alt., paniculadas o racemosas, laxas, erectas o ascendentes; brácteas lanceoladas u ovadas; bractéolas numerosas, deciduas o persistentes; bractéolas de segundo orden escariosas; pedicelos cortos de 0,4-3,5 mm long. Flores perfectas, de 40-50 mm long., péndulas, glabras a glabrescentes. Tépalos 6, 2-seriados, algo suculentos, linearoblongos a oblongo-espatulados, agudos, de 33 $40 \times 3,5-7 \mathrm{~mm}$, los internos con una costilla en su dorso, papilosos, rojos o verde-amarillentos; estambres 6, filamentos filiformes, ca. $35 \mathrm{~mm}$ long., inclusos; ovario ínfero, cilíndrico, ca. $20 \mathrm{~mm}$ long., rojo oscuro, estilo filiforme, estigma ciliado. Cápsulas loculicidas, oblongas a subglobosas, de $30-40 \times 15-25 \mathrm{~mm}$; semillas numerosas, planas, negruzcas.

Distribución y hábitat. Casual. Nativa del centro y sur de México, cultivada ampliamente en regiones cálidas y templadas de todo el mundo (GarcíaMendoza, 1987; Thiede, 2001; Hurrell et al., 2005). Se la cultiva como ornamental en la Argentina (Dimitri, 1987); en Córdoba se ha escapado de cultivo y crece en terrenos modificados de las Sierras Chicas.

\section{Nombre vulgar. "Beschorneria".}

Material estudiado. ARGENTINA. Prov. Córdoba. Dpto. Punilla, Valle Hermoso, Villa Yacoana, 31 $08^{\circ} 12,3$ 'S, 64²8'51,5 W, $855 \mathrm{~m}$, J. J. Cantero 7141 (9-VI-2015) \& 7159 (1-IX-2015) (CORD).

Ophiopogon japonicus (L.f.) Ker Gawl., Bot. Mag. 27: t. 1063. 1807.

Basónimo: Convallaria japonica L.f., Suppl. Pl.: 204. 1782. Tipo. "Habitat in Iaponia. Thunberg." (Holotypus, n.v.). Fig. 4 F.

Hierbas estoloníferas. Raíces moderadamente engrosadas, usualmente con porciones tuberosas hacia el medio y el extremo. Hojas basales arrosetadas, sésiles, graminoides, 3-7-nervias, margen serrulado. Escapos de 6-15 cm long., más cortos que las hojas. Inflorescencia en panícula reducida, de $2-5 \mathrm{~cm}$ long., 10-flora o más; brácteas lanceoladas, de 7-8 mm long. Flores solitarias o geminadas; pedicelo de 3-4 mm long., 
articulado en la parte media. Tépalos blancos o purpúreos, lanceolados, ca. 5 × $2 \mathrm{~mm}$; filamentos estaminales muy cortos, anteras de 2,5-3 mm long.; estilo estrechamente cónico, ca. $4 \mathrm{~mm}$ long., moderadamente grueso hacia la base; semillas globosas, de 7-8 mm diám.
Distribución y hábitat. Casual. Nativa de Japón, Corea, China continental y Taiwán (Xinqi \& Tamura, 2000). En la Argentina se cultiva como ornamental (Dimitri, 1987; Hurrell et al., 2005); en la provincia de Córdoba se ha encontrado en bordes de caminos serranos.
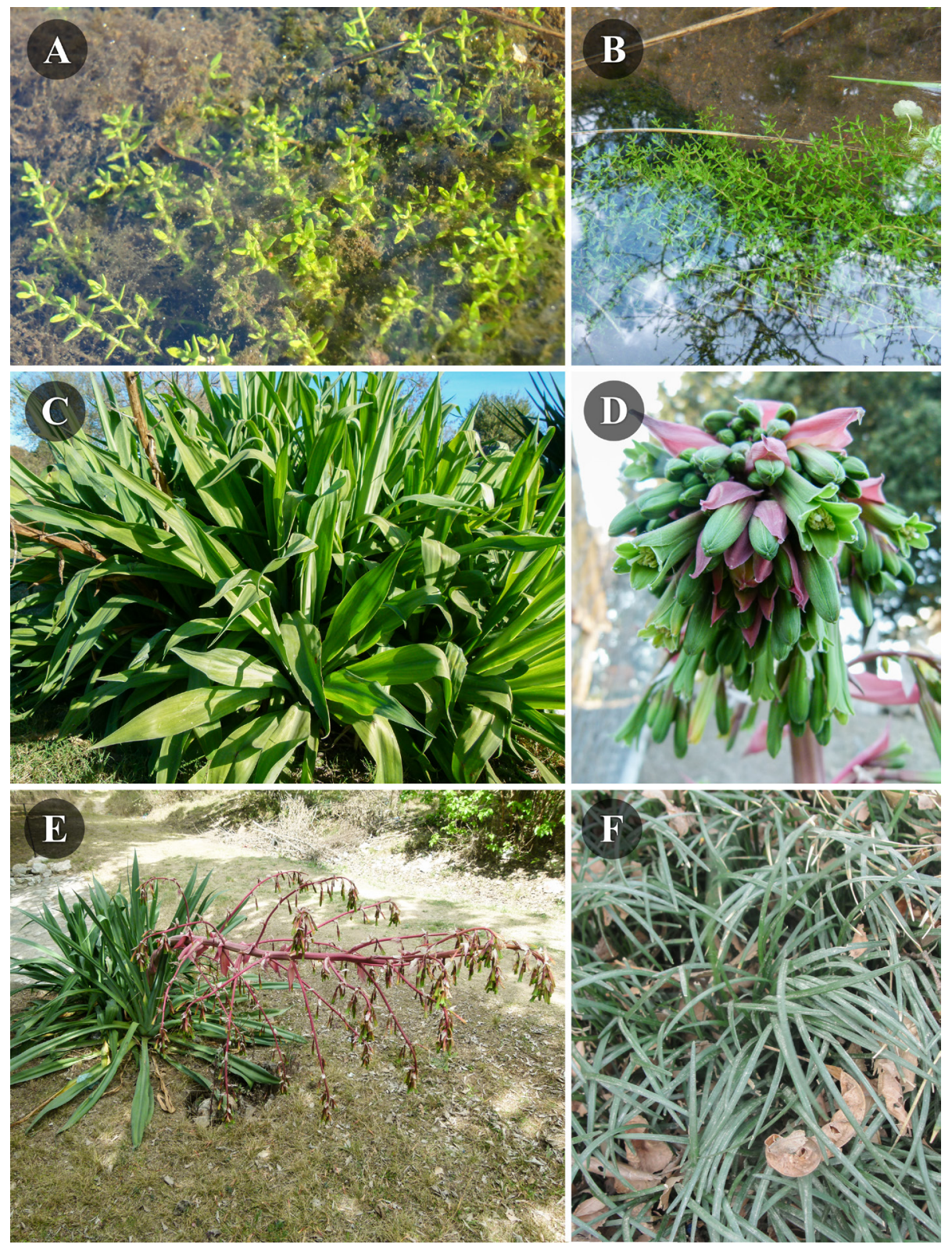

Fig. 4. A, B: Crassula venezuelensis. C-E: Beschorneria yuccoides. F: Ophiopogon japonicus. A, C, F: Planta. B: Hábito. D: Detalle de inflorescencia. E: Planta con inflorescencia. 


\section{J. J. Cantero et al. - Novedades para la flora de la Argentina}

Nombre vulgar. "Pasto inglés".

Material estudiado. ARGENTINA. Prov. Córdoba. Dpto. Río Cuarto, Las Albahacas, cercanías entrada del pueblo, 31-VII-2015, J. J. Cantero 7150 (CORD).

\section{Asteraceae}

Erigeron karvinskianus DC., Prodr. [A. P. de Candolle] 5: 285. 1836. Tipo: MÉXICO, Karwinski s.n. (Holotypus M0029742!). Fig. 5.

Sufrútice bajo, con ramitas delgadas, color
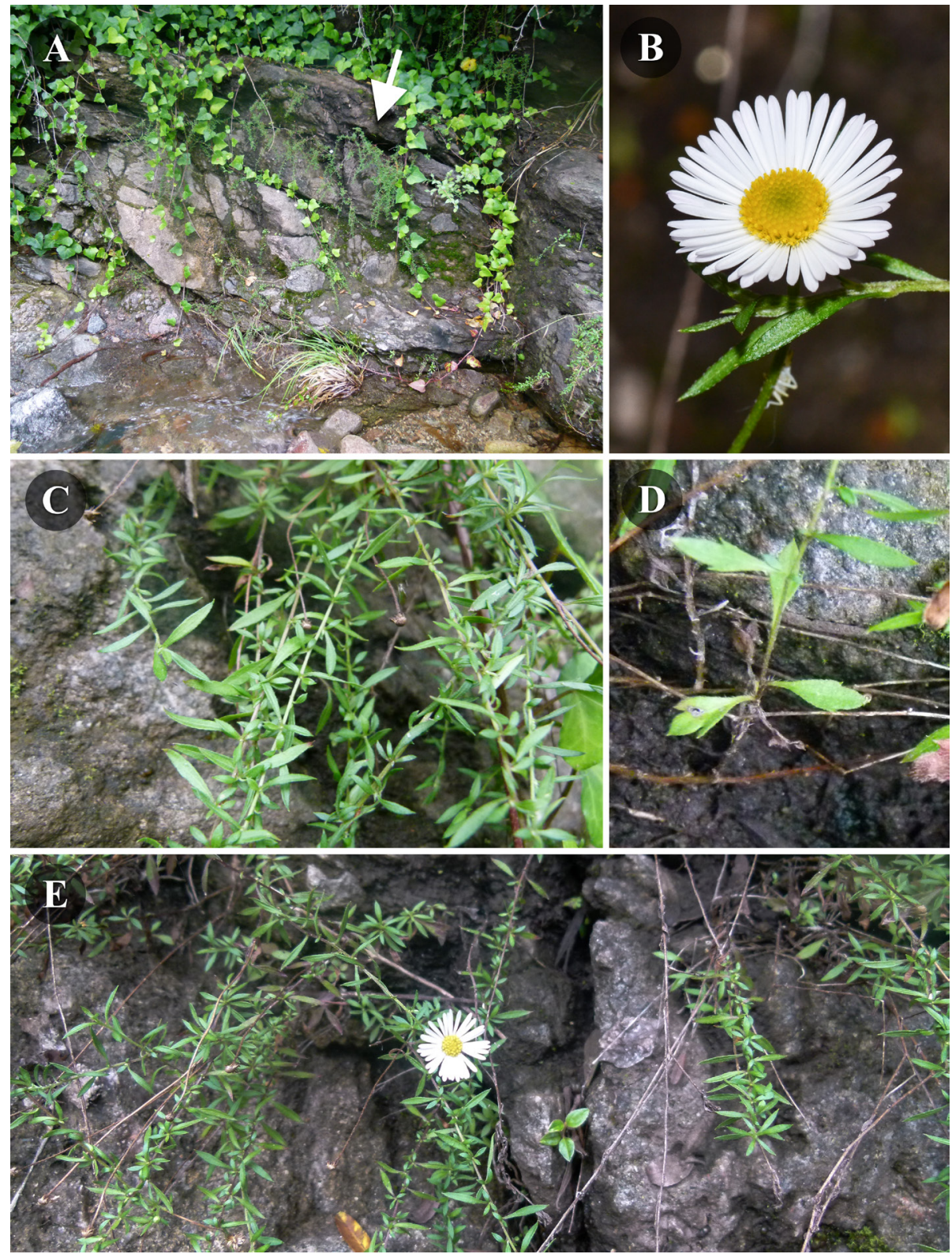

Fig. 5. Erigeron karvinskianus. A: Hábitat (especie indicada con la flecha). B: Capítulo. C: Rama con hojas. D: Detalle de hoja basal. E: Hábito. 
caoba, con pelos ralos hacia el ápice. Hojas angostamente lanceoladas hasta linear-lanceoladas, hacia arriba enteras, las inferiores, varias con dientes gruesos, algo pubescentes sobre la nervadura media y márgenes (a veces, algunas agrupadas en braquiblastos). Capítulos radiados sobre largos pedúnculos, solitarios o en panículas laxas. Involucro acampanado, con brácteas 2-3-seriadas, linear-lanceoladas con margen hialino, glabras o algo pubescentes. Flores del radio con lígula angosta, blanca (a veces algo liláceas); flores del disco tubulosas, amarillas. Aquenios cilíndricos, con pubescencia laxa. Papus blanco.

Distribución y hábitat. Casual. Especie descripta para México; habita América Central, y se extiende por Colombia y Venezuela, hasta el centro de Chile (Solbrig, 1962). Al igual que en Chile, tal vez se trate de un "escape de cultivo", puesto que hay colecciones de su cultivo en 1995 y 1996 (Ariza Espinar 3202 \& 3241, CORD), aunque la presente muestra proviene de lugares muy prístinos de las Sierras Chicas de Córdoba, muy alejado de zonas pobladas. En este ambiente, crece como casmófita en sitios umbrosos.

Material estudiado. ARGENTINA. Prov. Córdoba. Dpto.Punilla, Río Cruz Grande, $30^{\circ} 17^{\prime} 02^{\prime \prime} / 30^{\circ} 57^{\prime} 54^{\prime \prime} \mathrm{S}, 64^{\circ} 28^{\prime} 56^{\prime \prime} " 64^{\circ} 29^{\prime} 05^{\prime \prime} \mathrm{W}$, 1203-1218 m, J. J. Cantero 7188 (18-I-2016) \& 7200 (14-II-2016) (CORD)

\section{Cupressaceae}

Hesperocyparis arizonica (Greene) Bartel, Phytologia 91(1): 180. 2009.

Basónimo: Cupressus arizonica Greene, Bull. Torrey Bot. Club 9 (5): 64. 1882. Tipo. U.S.A. Arizona: Clifton, on the mountains back of Clifton, 1-XI-1880, Greene s.n. (Lectotypus NDG 05825!, designado por Little, Syst. Bot. 31 (3): 473. 2006). Fig. 6 A, B.

Árboles hasta de 15-18 m alt. Tronco corto, ramoso; corteza de arboles jóvenes separándose en grandes y delgadas escamas, dejando al descubierto la corteza nueva rojiza; en individuos añosos, corteza fibrosa y castaño-oscura; ramitas cuadrangulares, gris oscuras; yemas de invierno diminutas, desnudas. Hojas escuamiformes, ca. 1,5 mm long., verdegrisáceas a plateadas, provistas o no de glándula resinosa dorsal. Amentos masculinos, oblongos, amarillos. Conos femeninos subglobosos, de 2-2,5 $\mathrm{cm}$ diám., castaño-rojizo oscuros, pedunculados, compuestos de 6-8 escamas peltadas, con umbo curvado y grueso. Semillas numerosas, de 1,5-3 $\mathrm{mm}$ long., oblongas a triangulares, castaño-rojizas, con alas muy angostas, laterales.

Distribución y hábitat. Casual. Especie nativa de Arizona (Estados Unidos) y el norte de México (http://www.conifers.org/cu/Cupressus_arizonica. php). En nuestro país, se ha hallado creciendo escapada de cultivo en un área de las Sierras Chicas, provenientes de individuos cultivados como ornamentales.

Nombres vulgares. "Ciprés arizónico", “ciprés de Arizona".

Material estudiado. ARGENTINA. Prov. Córdoba. Dpto. Punilla, Casa Grande, $31^{\circ} 08^{\prime} 42^{\prime \prime} \mathrm{S}$, 64²9'14' 'W, J. J. Cantero 7155 (CORD).

\section{Iridaceae}

Iris germanica L., Sp. Pl. 1: 38. 1753. Tipo. "Habitat in Germaniae editis" (Lectotypus Herb. Clifford: 18, Iris 2, BM 000557643!, designado por Mathew in Jarvis \& al., Regnum Veg. 127: 57. 1993). Fig. 6 C, D.

Hierbas perennes, algo glaucas. Rizomas \pm horizontales, ramificados, con numerosas raíces fibrosas. Tallos aéreos hasta ca. $1 \mathrm{~m}$ alt., cilíndricos, lisos, sólidos, a menudo con restos foliares secos, grisáceos. Hojas ensiformes, persistentes; las basales de 28-46 x 1,5-4 cm, erguidas o ligeramente curvadas en el ápice, glabras; las caulinares de 11-23 x 1-2,5 $\mathrm{cm}$. Ramas de la inflorescencia alargadas, hasta de $10 \mathrm{~cm}$ long., sobrepasando a las brácteas; brácteas 2 , de 2,6-5 cm long., anchamente ovadas a obovadooblongas, glabras. Flores 2-6, pediceladas, fragantes; tubo periántico de 15-30 mm long., cilíndrico, algo ensanchado en el ápice; tépalos externos de 5-9 x 3,5$5 \mathrm{~cm}$, erecto-patentes, limbo obovado, gradualmente estrechado hacia la base, muy recurvado, de color morado, violeta-purpúreo o violeta claro, raro blanco, con tonalidades violetas en la base, con área basal más clara, blanco-amarillenta o azulada, con nervios radiales violeta-purpúreos o castaños, en la que se inicia una densa barba de pelos hasta de 6 


\section{J. J. Cantero et al. - Novedades para la flora de la Argentina}

mm long., amarillentos o blanquecinos con el ápice amarillo, que se prolonga hacia la base del tépalo, donde se tornan anaranjados; tépalos internos de 5-9 x 3,8-5 cm, violeta claros, erectos, incurvados y conniventes, anchamente oblongos a suborbiculares, adelgazados en una uña notoria, muy acanalada, violeta, con pequeñas manchas y líneas más oscuras que se prolongan hacia la base del limbo; ovario prismático, poco más ancho que el tubo periántico, láminas estilares de 2,5-3,5 mm long., de color violeta pálido o blanquecino, con el nervio central y los lóbulos de color violeta algo más oscuro, recurvadas, de subespatuladas a oblanceoladas. Cápsulas no vistas.
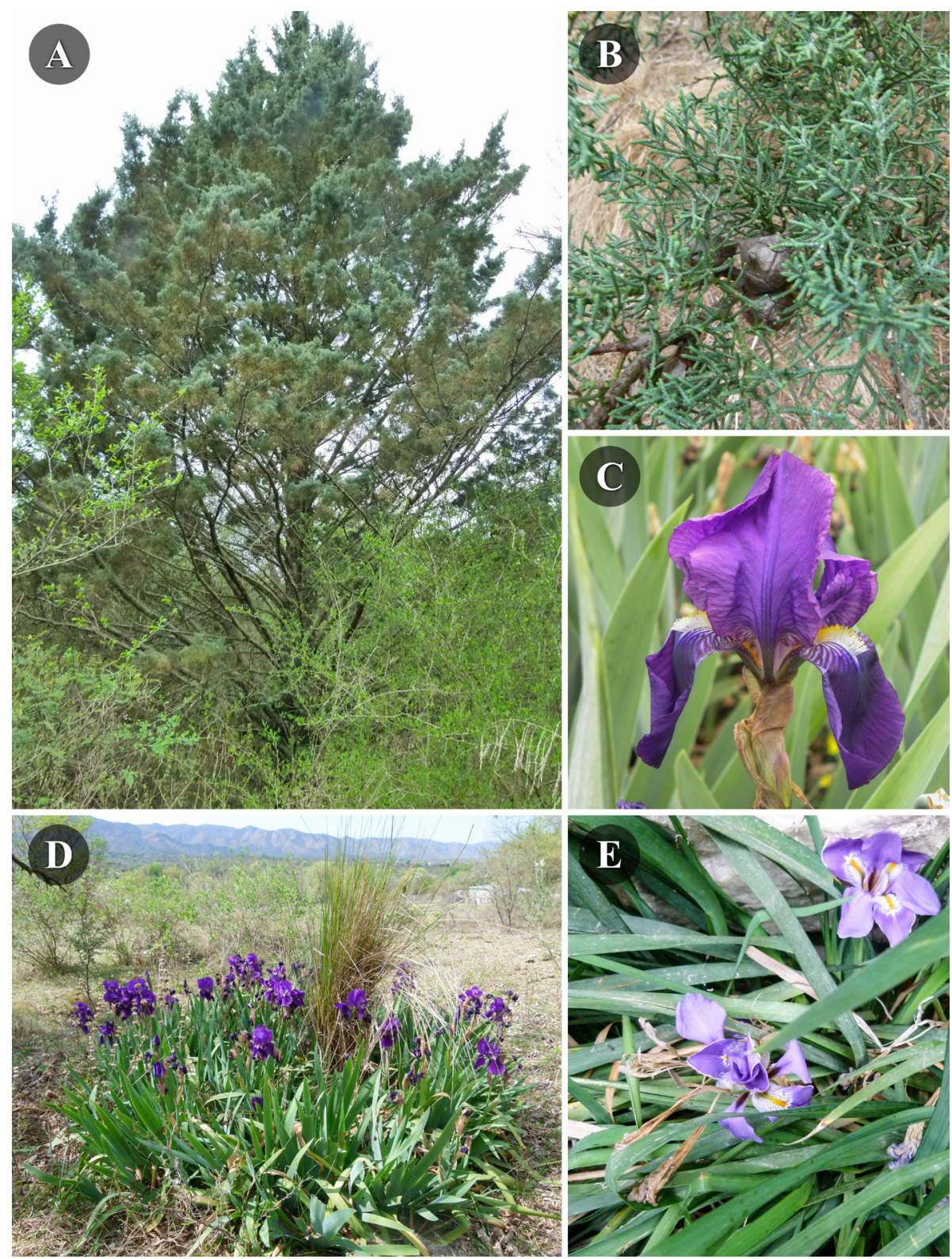

Fig. 6. A, B: Hesperocyparis arizonica. C, D: Iris germanica. E: Iris unguicularis. A, D: Hábito. B: Conos. C: Flor. E: Planta con flores. 
Distribución y hábitat. Casual. Especie nativa del centro y sur de Europa (Crespo, 2013). Cultivada como ornamental en todo el mundo. En la Argentina, fue coleccionada escapada de cultivo en bordes de habitaciones abandonadas, en una localidad de las Sierras del Sur de Córdoba.

Nombres vulgares. "Lirio azul”, "lirio común”.

Material estudiado. ARGENTINA. Prov. Córdoba. Dpto. Punilla, Casa Grande, $31^{\circ}$ 08'29' 'S, 64²8'40" W, 13-IX-2015, J. J. Cantero 7153 (CORD).

Iris unguicularis Poir., Voy. Barbarie 2: 86. 1789. Tipo: ÁFRICA. [Algeria]: Barbarie, J. L. M. Poiret s.n. (Holotypus P 00439299!, isotypus MPU 017360!). Fig. 5 E.

Hierbas perennes, acaules. Rizomas fuertes, con raíces rígidas formando matas densas. Hojas rosuladas, lineares a ensiformes, de 12-50 x 0,3-1 $\mathrm{cm}$, con nervios marcados. Valvas de la espata de 6-13 cm long., herbáceas. Flores perfumadas sobre escapos 1-floros, lilas, cortamente pediceladas; tubo del perigonio cilíndrico, de 6-22 cm long.; tépalos externos oblanceolado-espatulados, de 5,5-8 x 1,8$3,2 \mathrm{~cm}$, de color azul-lavanda a liláceos o blancos, con nerviación más oscura en la región blanca de la base con una banda media amarilla; tépalos internos oblanceolado-espatulados, unguiculados y agudos, de 6,2-8,6 x 1,7-3 cm, del color de los tépalos externos, a excepción de una zona violeta-oscura hacia la base; tubo estilar de 20 $25 \mathrm{~mm}$ long., ramas estilares de 27-35 mm long., serruladas a laciniadas. Cápsulas elipsoides, de 30$40 \mathrm{~mm}$ long, brevipediceladas; semillas anaranjadoamarronadas, pocas, globosas a ovoides, de 6,5 $\mathrm{mm}$, rugosas a ruminadas.

Distribución y hábitat. Casual. Especie nativa del norte de África (Davis \& Juri, 1990), muy cultivada como ornamental, en especial para formar borduras. En la Argentina, se ha registrado escapada de cultivo en un sitio con residuos de material verde proveniente de arreglos de jardines, en una localidad de las Sierras del Sur de Córdoba.

Material estudiado. ARGENTINA. Prov. Córdoba. Dpto. Punilla, cercanías del Arroyo
Vaquerías, $31^{\circ} 08^{\prime} 24^{\prime}$ S, $64^{\circ} 28^{\prime} 35,8^{\prime \prime} \mathrm{W}, 823 \mathrm{~m}$, 19-V-2015, J. J. Cantero 7081 (CORD).

\section{Myrtaceae}

Eucalyptus cinerea F.Muell. ex Benth., Fl. Austral. 3: 239. 1867. Tipo. AUSTRALIA. "N. S. Wales: Lachlan river, near Bathurst, A. Cunningham [39]; also Lake George, herb. F. Mueller" (Syntypus Cunningham 39, K 000279802!). Fig. 7 A, B.

Árboles hasta ca. $15 \mathrm{~m}$ alt.; corteza fibrosa, áspera, gruesa, persistente, de color pardusco. Hojas opuestas, sésiles, concoloras, pruinosas, plateadas; hojas juveniles orbiculares a ovadas, algo cordiformes en la base, glaucas, de 3-4 x 1,6-2 $\mathrm{cm}$; hojas adultas anchamente elípticas a elípticas, de 7-10 cm long., glaucas o verde-grisáceas. Inflorescencias umbeliformes, 3-floras, pedúnculos cilíndricos o 4-angulares, de 3-5 mm. Flores sésiles a subsésiles. Botones florales ovoides o apenas fusiformes, de 5-7 mm diám, con opérculo cónicoapiculado; tubo receptacular obcónico de igual longitud que el opérculo; estambres todos fértiles, anteras ovoides, con una glándula bien evidente en el tercio superior. Frutos cónicos a cilíndricos, 6-8 mm diám., con reborde ancho y separado del tubo receptacular por un canalículo, 3-4-valvares, valvas triangulares, apenas exertas; semillas oscuras y rugosas.

Distribución y hábitat. Casual. Es nativa de las montañas del sureste australiano (Chippendale, 1988; Hill, 1991). En nuestro país, se cultiva como ornamental y para la venta de sus ramas en florería y, fue detectada escapada de cultivo y espontánea en bordes de forestaciones de las Sierras del Sur de Córdoba.

Obs. A pesar de que la concentración de los aceites esenciales en hojas, flores y frutos de esta especie, así como el valor de su componente principal (eucaliptol) es alto, tiene pocos registros como planta medicinal. Posee un alto potencial de uso para fines terapéuticos y como aditivos naturales en alimentos, cosmética y perfumes (Mendes Silva et al., 2011).

Nombres vulgares. "Eucalipto cinéreo", "eucalipto plateado". 


\section{J. J. Cantero et al. - Novedades para la flora de la Argentina}

Material estudiado. ARGENTINA. Prov. Córdoba. Dpto. Calamuchita, Villa Alpina, 31 ${ }^{\circ} 57^{\prime} 55^{\prime}$ 'S, 64\%48'42”W, 1313 m, 25-V-2015, J. J. Cantero 7114 (CORD). Dpto. Río Cuarto, Las Higueras, $33^{\circ} 06^{\prime} 47^{\prime \prime} \mathrm{S}, 64^{\circ} 18^{\prime} 04^{\prime \prime} \mathrm{W}, 424 \mathrm{~m}, 3-\mathrm{VI}-$ 2015, J. J. Cantero 7135 (CORD).
Eucalyptus sideroxylon A.Cunn. ex Woolls, Proc. Linn. Soc. New South Wales ser. 2, 1:859. 1886. Tipo. AUSTRALIA. New South Wales: Lachlan River, VI-1817, Cunningham 205 (Holotypus K 000347657!; isotypi: BM 001015318!, CANB 435302!; CANB 452128!). Fig. 7 C, D.
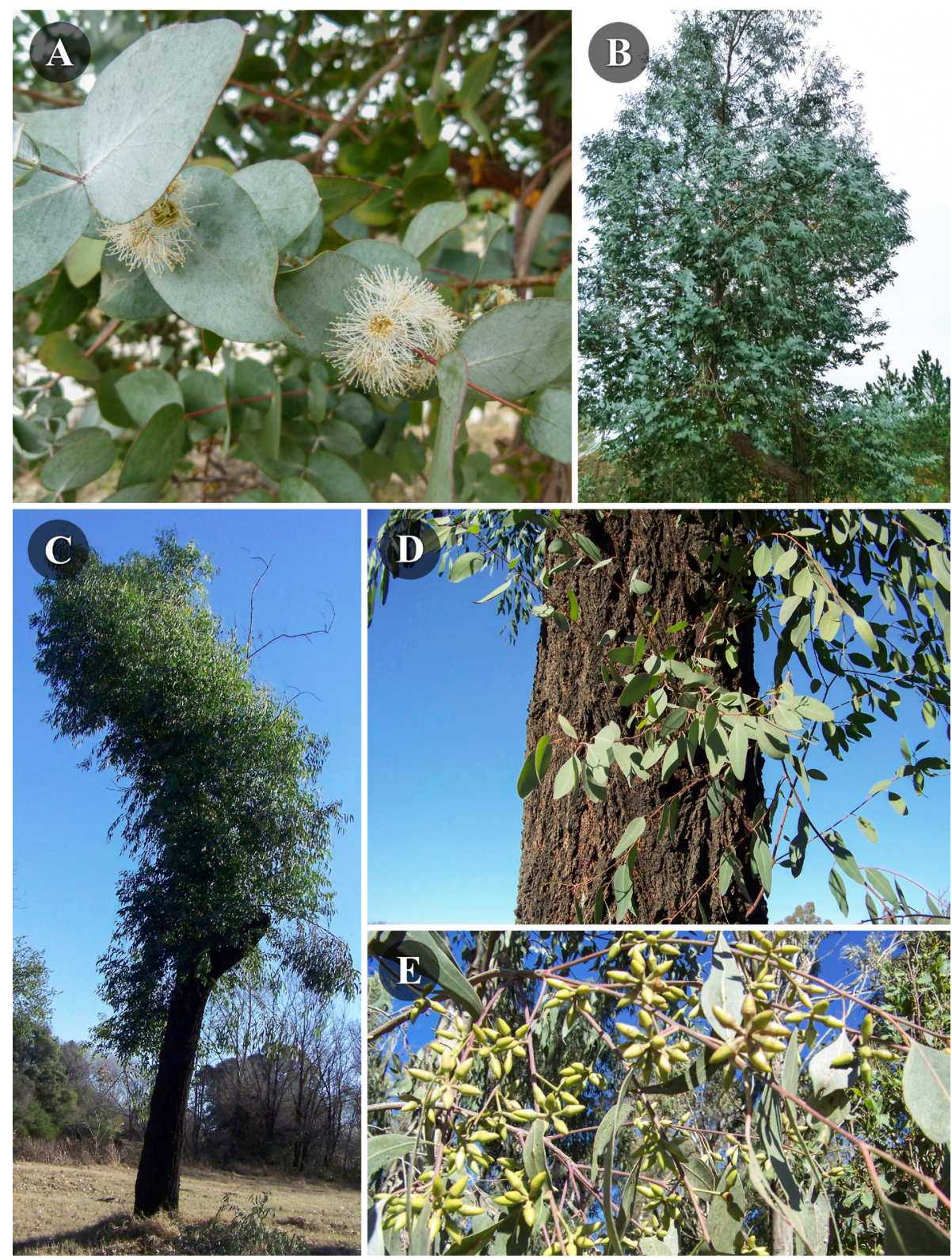

Fig. 7. A, B: Eucalyptus cinerea. C, D: Eucalyptus sideroxylon. E: Eucalyptus tereticornis. A: Rama con flores. B, C: Hábito. D: Corteza y hojas. E: Frutos. 
Árboles hasta ca. $35 \mathrm{~m}$ alt.; corteza fisurada, rugosa, dura, persistente, de color negro o rojonegruzco. Hojas alternas, pecioladas, concoloras, con glándulas translúcidas; hojas juveniles lineares a elípticas u ovadas; hojas adultas elípticas, de $7-11,5$ x 2-2,8 cm, pecíolos rojizos, de 0,5-1,8 cm long. Inflorescencias umbeliformes, (3) 5-7-floras, pedúnculos cilíndricos o cuadrangulares, largos, de 1,4-1,6 cm. Flores rosadas, rojizas o blancas, pedicelos de 0,8-1,2 cm. Botones florales ovoides a cortamente fusiformes, a veces glaucos, de 4-7 mm diám, con opérculo cónico o apenas rostrado, de 3-5 x 4-5 $\mathrm{mm}$; tubo receptacular turbinado y liso, apenas más largo y más ancho que el opérculo; estambres externos estériles, anteras cuboides, truncadas. Frutos globosos a ovoides, lisos, de 8-10 mm diám., con reborde angosto, 5-valvares, valvas completamente incluidas; semillas castaño-oscuras, aplanadas.

Distribución y hábitat. Casual. Especie nativa del sureste australiano (Chippendale, 1988; Hill, 1991). En nuestro país se cultiva como forestal y ornamental, siendo uno de los eucaliptos más decorativos (Dimitri, 1987). Se ha encontrado escapada de cultivo en un borde de un monte forestal en planicies aluviales del Río Cuarto, Córdoba.

Nombre vulgar. "Eucalipto sideroxylon".

Material estudiado. ARGENTINA. Prov. Córdoba. Dpto. Río Cuarto, Las Higueras,

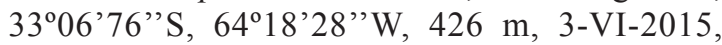
Cantero 7134 (CORD).

Eucalyptus tereticornis Sm., Spec. Bot. New Holland 4: 41. 1795. Tipo. AUSTRALIA. New South Wales, Port Jackson, White s.n. (Holotypus LINN, isotypus BM 001015287!). Fig. 7 E.

Árboles hasta ca. $50 \mathrm{~m}$ alt.; corteza lisa, blanquecina o grisácea, que se deprende en forma de tiras o flecos. Hojas alternas, pecioladas, concolores; hojas juveniles elípticas a anchamente ovadas, verde brillante, de 5,5-8 x 2,5-3,5 cm; hojas adultas angosto-elípticas a elípticas, a veces falcadas, largamente acuminadas, de (12) 14,515,5 (18) x 2,8-3,4 cm, verde pálidas, pecíolos de 2,5-3 cm. Inflorescencias umbeliformes, (4)7-floras (raro más), a veces 2 por nudo, pedúnculos cilíndricos o angulares, de 1,2-1,7 cm. Flores blancas, pedicelos gruesos, de 3-8 $\mathrm{mm}$ long. Botones florales cilíndricos a fusiformes, de 10-20 x 4-8 mm diám, con opérculo cónico o elongado-agudo, unas 2,5 veces más largo que el tubo receptacular; estambres exteriores no inflexos en el botón, anteras ovoides, con una glándula subapical o dorsal. Frutos globosos u ovoides, ca. 8-10 mm diám., con reborde convexo evidente, 3-5-valvares, valvas bien exertas; semillas negras, angulosas, rugosas.

Distribución y hábitat. Casual. Especie nativa del este australiano (Chippendale, 1988; Hill, 1991). En nuestro país se cultiva como ornamental, forestal y para constituir montes de sombra y abrigo (Mangieri \& Dimitri, 1961). Se la ha registrado escapada de cultivo en un borde de un monte forestal en planicies aluviales del río Cuarto.

Nombre vulgar. "Eucalipto tereticornis".

Material estudiado. ARGENTINA. Prov. Córdoba. Dpto. Río Cuarto, Las Higueras, $33^{\circ} 06^{\prime} 42^{\prime \prime S}, 64^{\circ} 18^{\prime} 58^{\prime \prime} \mathrm{W}, 425$ m, 3-VI-2015, J. J. Cantero 7132 (CORD).

\section{Oleaceae}

Jasminum mesnyi Hance, J. Bot. 20: 37. 1882. Tipo: CHINA, GUIZHOU: Mei-chu-chiu, ca. 2000 m, 11-IV-1880, W. Mesny s.n., Herb. Hance-21211 (Holotypus BM 000997669!). Fig. 8 A.

Arbustos glabros, apoyantes o escandentes, perennifolios o deciduos, muy ramificados. Tallos largos, delgados, tetrágonos y arqueados, a veces forman matas de 1,5-3 $\mathrm{m}$ de alt. y diám. Hojas opuestas, trifolioladas, anchamente ovadas o elípticas, a veces suborbiculares, de 3-5 x 1,5-2,5 $\mathrm{cm}$, folíolos angosto-ovados u ovado-lanceolados, base cuneada, ápice obtuso o mucronulado, folíolo terminal con base decurrente en el peciólulo, los laterales sésiles, pecíolo de 0,5-1,5 cm long. Flores fragantes, por lo común solitarias, axilares raro terminales; pedicelos de 3-8 mm; brácteas foliosas, obovadas o lanceoladas; cáliz campanulado, lóbulos (5) 6-8 (10), foliáceos, lanceolados, de 4-7 mm long.; corola amarilla 


\section{J. J. Cantero et al. - Novedades para la flora de la Argentina}

infundibuliforme, de 2-4,5 cm diám., tubo de 1-1,5 cm long.; lóbulos (5) 6-8 (10), anchamente obovados u oblongos, de 1,1-1,8 cm long.; estambres 2, inclusos, insertos en la mitad del tubo corolino, filamentos cortos; óvulos 1 o 2 por lóculo; estilo filiforme. Bayas bilobadas o elipsoides por aborto de un carpelo, de 6-8 $\mathrm{mm}$ diám., negro brillante; semillas sin endosperma, embrión recto.

Distribución y hábitat. Casual. Es nativa de barrancas y bosques del sudoeste de China (Chang et al., 1996). En la Argentina es muy utilizada para cercos vivos. Se ha hallado escapada de cultivo en algunas localidades de las Sierras del Sur de Córdoba.
Nombre vulgar. "Jazmín amarillo".

Material estudiado. ARGENTINA. Prov. Córdoba. Dpto. Punilla, Casa Grande, $31^{\circ} 08^{\prime} 38^{\prime}$ S, 642ㅇ'57"W, $844 \mathrm{~m}, 19-\mathrm{V}-2015$, J. J. Cantero 7083 (CORD). Dpto. Río Cuarto, Los Cóndores, $3 \mathrm{~km}$ al sur rumbo a Berrotarán, 32²0'14" S, $64^{\circ} 17^{\prime} 32^{\prime}$ W, 823 m, 2-VII-2015, J. J. Cantero 7145 (CORD).

\section{Plumbaginaceae}

Ceratostigma plumbaginoides Bunge, Enum. Pl. Chin. Bor. [A.A. von Bunge]: 55. 1833. Tipo. "Hab. Prope Pekinum in umbrosis, ubi unicum tantum specimen florens legi initio julii" (Holotypus, n.v.). Fig. 8 B.
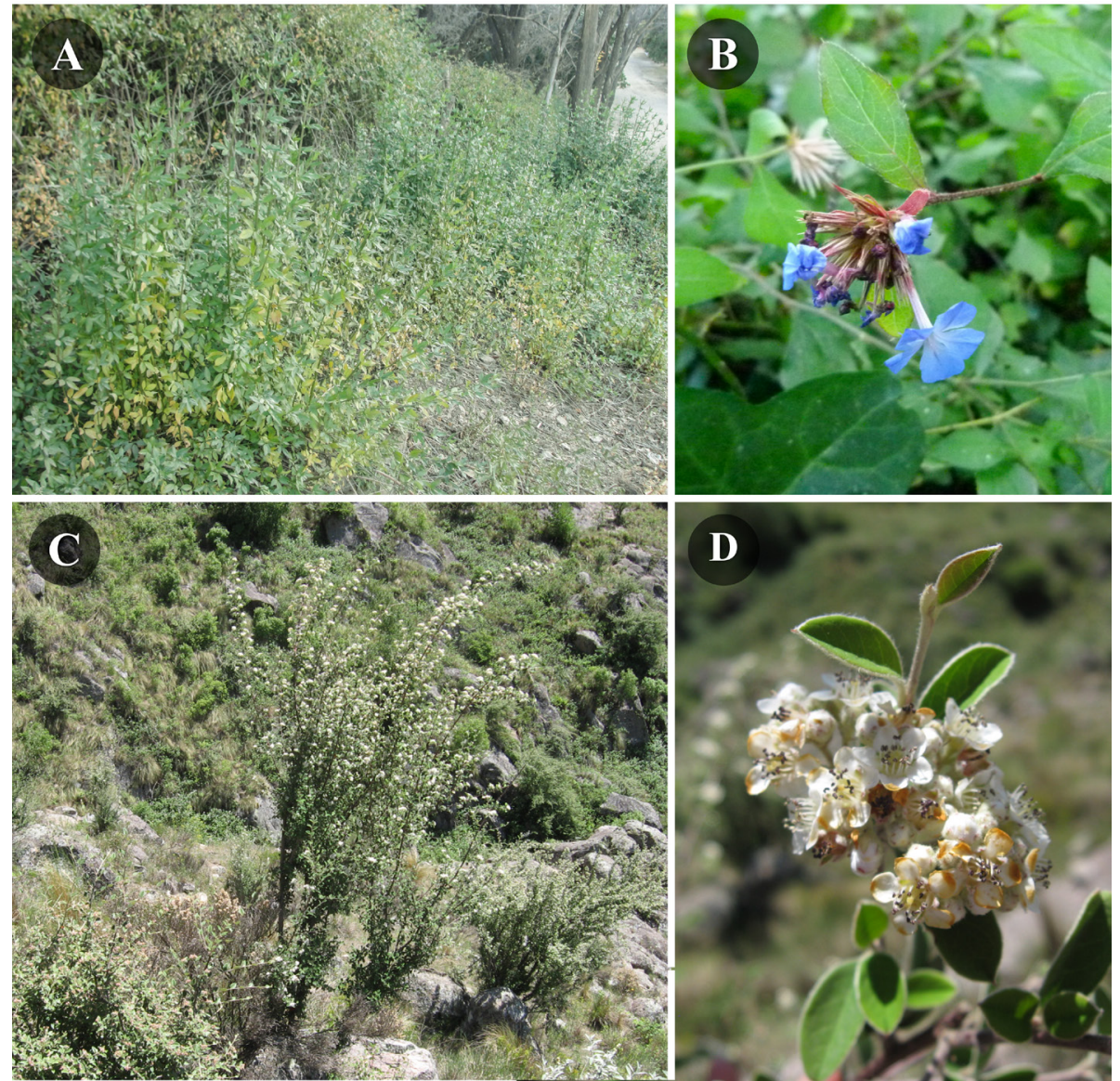

Fig. 8. A: Jasminum mesnyi. B: Ceratostigma plumbaginoides. C, D: Cotoneaster pannosus. A, C: Hábito. B, D: Flores. 
Hierbas perennes, de 20-60 cm alt. Rizomas ramificados con una escama ovada en cada nudo. Tallos aéreos angulosos, simples o muy ramificados, rojizos, híspidos hacia el ápice. Hojas alternas, enteras, anchamente ovadas a obovadas, de 4-6 (10) x 2-3 (5) cm, glabrescentes o glabras, margen ciliado. Inflorescencias terminales o axilares, con 15-30 flores o más, cada flor con una bráctea lanceolada a oblonga, escariosas, con tintes rojizos, cuspidadas, ciliadas. Cáliz de (12) 13-15 mm long., tubuloso, solo con pelos estrigosos esparcidos a lo largo de las costillas, con 5 dientes subulados ca. 2 $\mathrm{mm}$ long.; corola hipocraterimorfa, de 2,5-2,8 cm long., tubo purpúreo más largo que el cáliz, limbo azul-azul purpúreo, con 5 lóbulos extendidos, diminutamente dentados, emarginados en el ápice, de $8 \times 8 \mathrm{~mm}$; estambres 5, monadelfos, algo exertos, anteras lineares, azules; ovario elipsoide, estilo glabro, incluso y más corto o más largo que los estambres (heterostilia presente), estigmas 5, lineares. Cápsulas ovoide-elipsoides, ca. 6 mm long., castaño-amarillentas; semillas castañorojizas.

Distribución y hábitat. Casual. Originaria de China, es una ornamental muy cultivada (TseHsiang \& Kamelin, 1996). Se la ha encontrado escapada de cultivo en sitios umbrosos y húmedos en una localidad de las Sierras del Sur de Córdoba.

Material estudiado. ARGENTINA. Prov. Córdoba. Dpto. Punilla, Dique San Jerónimo, 30 58'66"S, 64²7'40”W, 1298 m, 31-V-2015, J. J. Cantero 7130. "Umbrófila, en márgenes de arroyo y saltos de agua serranos" (CORD).

\section{Rosaceae}

Cotoneaster pannosus Franch., Pl. Delavay.: 223. 1889. Tipo. [CHINA]. "Yun-nan, in declivibus calcereis montis Hee-chan-men, alt. 2500 m.; fl. 22 maj. 1886 (Delavay, n. 3741, 3746, 3745, 2538); in collibus calcareis ad Yang-in-chan, supra Mo-soyn; fl. 7 jun. (Delavay, n. 3544); in fructicetis circa Tapin-tze (id. n. 3743)" (Syntipi Delavay n. 3741: A 00104345!, n. 3745: P 00601388!, n. 2538: P 00601192!, n. 3544: K 000758558!). Fig. 8 C, D.

Arbustos semi-perennifolios, hasta ca. $2 \mathrm{~m}$ alt. Ramas grisáceas o purpúreo-castañas, estriadas, densamente blanco-tomentosas cuando jóvenes, luego glabrescentes. Hojas coriáceas, estrechamente elípticas, elípticas u ovadas, base anchamente cuneada, ápice obtuso u agudo con un corto mucrón, de 1,8-2,5 x 0,8-1,5 cm, nervio central hundido adaxialmente, nervios laterales 4-6 pares, marcadamente discoloras, densamente albo-tomentosa en el envés, levemente pubescentes o glabras en el haz; pecíolo de 4-6 $\mathrm{mm}$ long., tomentoso; estípulas caducas, lineares, pubescentes. Inflorescencias en corimbos, de 1-2,5 cm long., con 10 a más flores; raquis y pedicelos densamente tomentosos; brácteas caducas, lineares, pubescentes. Pedicelos de 2-3 mm long.; flores de 7-8 mm diám., hipanto campanulado, densamente tomentoso abaxialmente; sépalos triangulares, ápice cortamente acuminado o agudo; pétalos extendidos, blancos, anchamente ovados o suborbiculares, de 3-3,5 mm long., pubérulos adaxialmente; estambres 20 , casi tan largos como los pétalos, anteras rojopurpúreas; ovario pubescente apicalmente, estilos 2-3, libres, casi tan largos como los estambres. Frutos rojo-oscuros, globosos u ovoides, de 7-8 mm diám., pirenos a menudo 2 .

Distribución y hábitat. Casual. Originaria de China (Lingdi \& Brach, 2003). Se la ha encontrado escapada de cultivo en laderas graminosas en una localidad de las Sierras del Sur de Córdoba.

\section{Nombre vulgar. "Cotoneaster".}

Material estudiado. ARGENTINA. Prov. Córdoba. Dpto. Calamuchita, La Cumbrecita, 31 ${ }^{\circ} 53^{\prime} 06^{\prime \prime} \mathrm{S}, 64^{\circ} 46^{\prime} 33^{\prime \prime} \mathrm{W}, 1642 \mathrm{~m}$, I. Lett s.n. (CORD). Idem, 31 52'56"S, 6446'54"W, 1695 m, I. Lett s.n. (CORD).

Prunus insititia L., Cent. Pl. I.: 12. 1755. Tipo. "Habitat in Anglia, Germania. Tyska Slån" (Neotypus Herb Linn 640.25!, designado por Ghora \& Panigrahi in Nayar et al., Fasc. Flora India, 18: 8. 1984). Fig. 9 A, B.

Arbustos o arbolitos hasta de $4 \mathrm{~m}$ alt., caducifolios, con ramas tortuosas, a veces espinosos. Tronco con lenticelas; corteza lisa, pardo-rojiza, brillante; ramas jóvenes grisáceas, pubescentes, pruinosas. Hojas en fascículos de 6-12 en cortos braquiblastos, de 2-6 x 1-4 cm, obovadas o anchamente elípticas, margen crenado o aserrado, dientes obtusos con 


\section{J. J. Cantero et al. - Novedades para la flora de la Argentina}

una pequeña glándula amarillenta en el ápice, cara adaxial verde oscura con algunos pelos simples en el nervio principal, cara abaxial glabrescente, base de la hoja y pecíolo de $0,7-1 \mathrm{~cm}$ long., con pelos simples en los márgenes; estípulas caducas, blanquecino-amarronadas, apicalmente 3-lobuladas, lóbulo superior más largo, bordes con dientes glandulíferos. Flores solitarias o en fascículos de 2-3, coetáneas respecto a las hojas nuevas o que las preceden; pérulas 3 , castañas o blanquecinas, ciliadas, cóncavas; receptáculo de 2- $3 \mathrm{~mm}$ long., campanulado, glabro; sépalos de
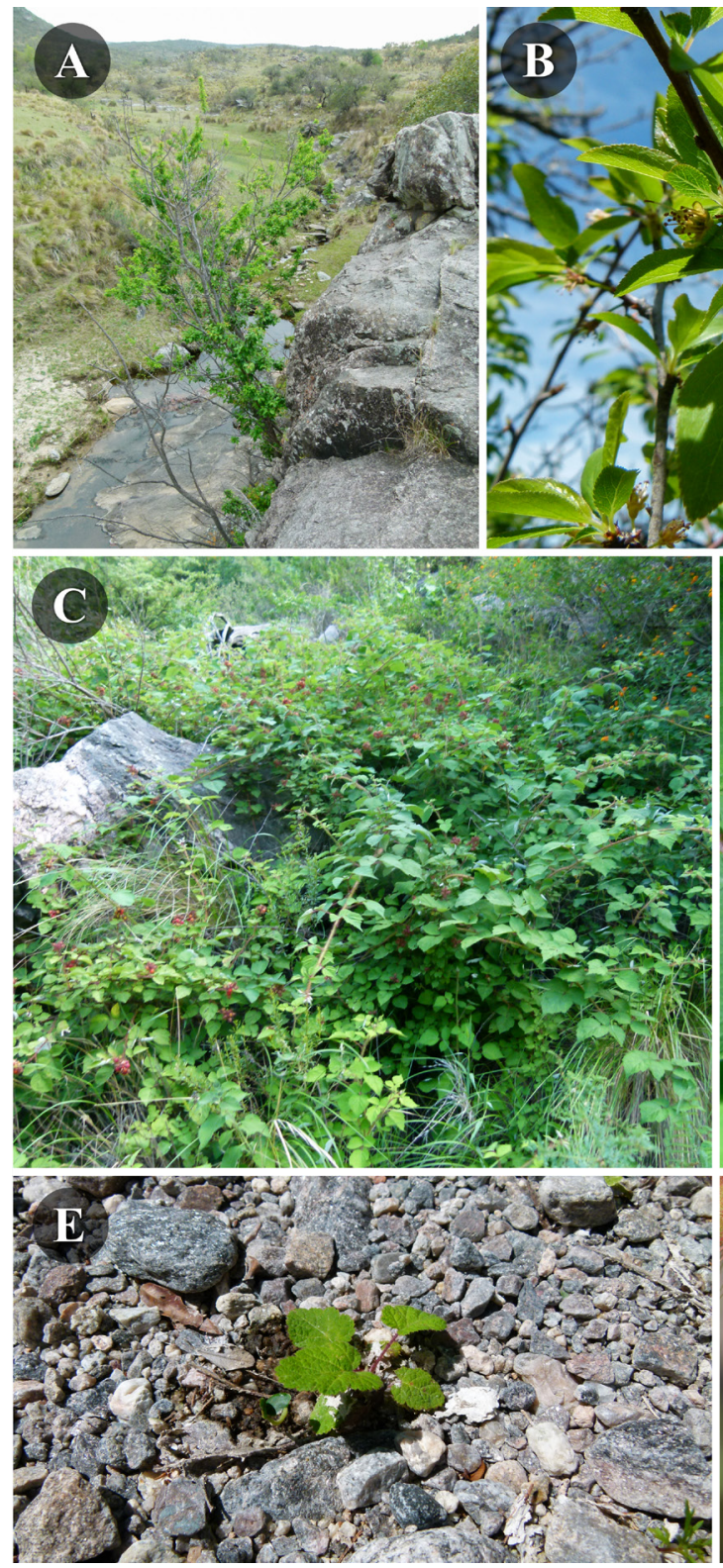
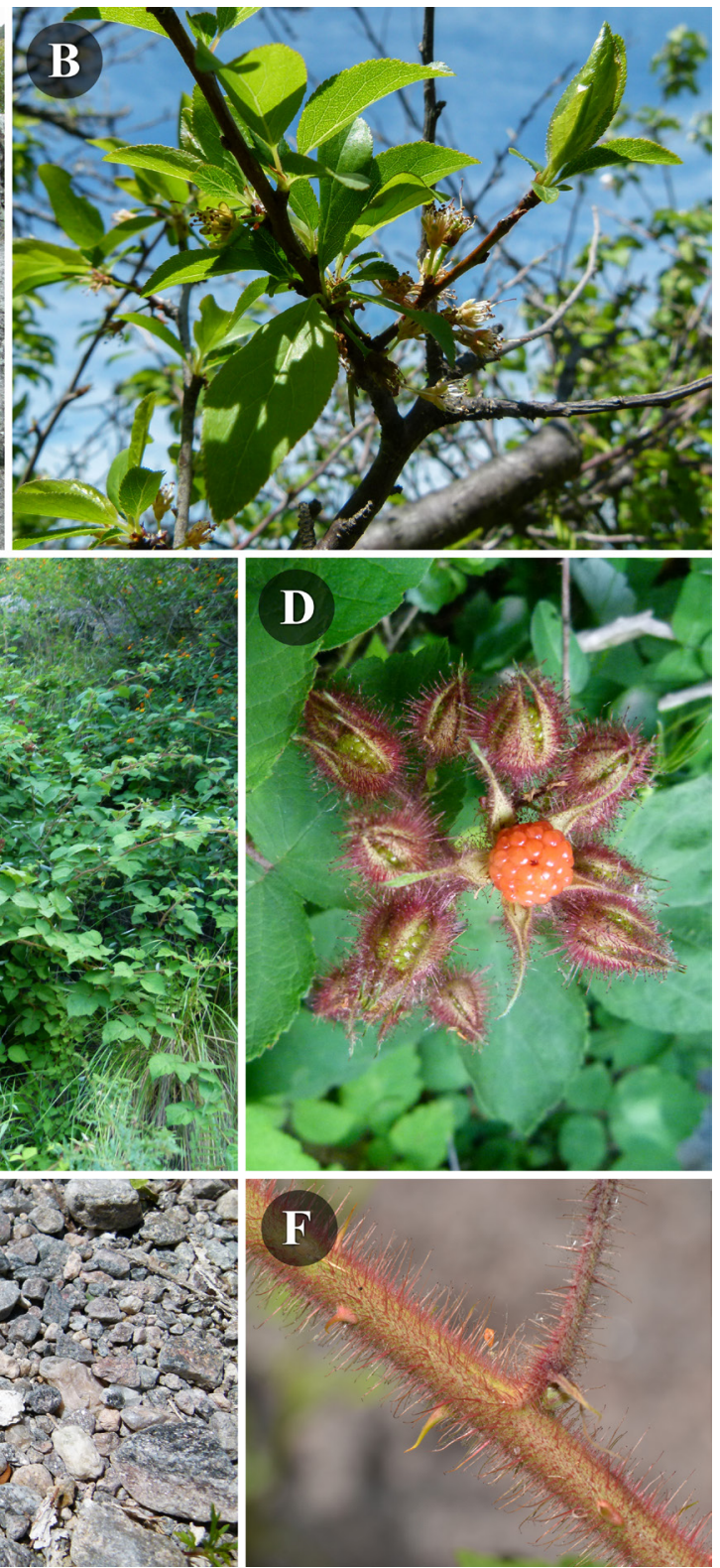

Fig. 9. A, B: Prunus insititia. C-F: Rubus phoenicolasius. A, C: Hábito. B: Rama florífera. D: Infrutescencia. E: Plántula. F: Tallo mostrando tricomas. 
2-4 mm long., erectos, ovados, obtusos, de ápice denticulado, margen membranáceo y blanquecino con pelos simples y glándulas; pétalos blancos de 6-8 x 4-5 mm, erectos o patentes, glabros, anchamente obovados; estambres más de 20, desiguales; gineceo ca. $9 \mathrm{~mm}$ long., superando a los estambres; ovario glabro, globoso, estilo verdoso, estigma discoideo. Frutos de 20-30 mm diám., subglobosos u ovoide-oblongos, rojizos, amarillentos o verdosos, pruinosos; mesocarpo de sabor ácido; endocarpo rugoso, ligeramente aquillado.

Distribución y hábitat. Casual. Especie originaria del centro y sur de Europa, norte de África y sudoeste de Asia (Blanca \& Díaz de la Guardia, 1998). En nuestro país, crece escapada de cultivo en el borde de un arroyo serrano en la Sierra de Comechingones. Es probable que estas plantas provengan de pies de porta-injertos fructificados, empleados en cultivos frutales en antiguos asentamientos de estas sierras.

Nombre vulgar. "Ciruelo silvestre".

Material estudiado. ARGENTINA. Prov. Córdoba. Dpto. Río Cuarto: Las Albahacas, 3252'57' S, 6450'41'”W, 776 m, 13-IX-2015, J. J. Cantero 7161 (CORD).

Rubus flagellaris Willd., Enum. Pl. [Willdenow] 1: 549. 1809. Tipo. "Habitat in America boreali". C.L. von Willdenow s.n. (Holotypus, B-W 09893010!).

Arbustos bajos, hasta ca. $2 \mathrm{~m}$ alt., armados. Tallos por lo general rastreros, decumbentes o apoyantes, muy largos, que arraigan por los ápices; ramas floríferas erectas, glabrescentes a densamente pilosas (pelos eglandulares largos y/o con pelos glandulares sésiles o cortos, dispersos); aguijones pocos a numerosos, rectos, patentes, algunos ligeramente retrorsos, de 1-4 (6) $\mathrm{mm}$ long. con base ensanchada; setas ausentes. Hojas deciduas, a veces semipersistentes, ternadas o palmati-compuestas (en turiones 5-7-foliadas), no lustrosas, margen moderada- a groseramente aserrado a doble aserrado o aserrado-dentado, apenas discoloras, epifilo glabrescente, hipofilo con escaso a numerosos pelos similares a los del tallo y con aguijones sobre el nervio medio y algunos laterales principales, pecíolos pilosos, armados, de 3-6 cm long.; folíolos $3(-5)$, el terminal anchamente ovado u ovado, de 4-9,5 x 3-7 cm, no lobado o apenas lobado, base redondeada a ligeramente cordada, peciólulo armado ca. $1 \mathrm{~cm}$ long.; folíolos laterales menores, sésiles, ovados o elípticos, base truncada o desigual; estípulas angosto-elípticas a lineares, de 3-20 mm long. Inflorescencias terminales o sobre cortos brotes aparentando ser axilares, racemiformes, con 1-3 flores. Pedicelos pilosos, con aguijones patentes, retrorsos o algo curvos; flores perfectas, de 3,2-3,6 $\mathrm{cm}$ diám.; sépalos anchamente triangulares, de 8-11 $\mathrm{mm}$ long.; pétalos blancos, elípticos u obovados, ápice retuso, de (8) 1,5-1,9 x 0,9-1 cm; filamentos filiformes; carpelos vellosos. Frutos rojizos a morados, comestibles, globosos (1-2 cm diám.) a cilindroides (1,5-3 x 0,8-1,4 cm); drupéolas 10-60, fuertemente coherentes al receptáculo formando una unidad, de 3-3,5 x 0,8-1 mm, con superficie reticulado-foveolada y pelos caducos.

Distribución y hábitat. Casual. Originaria de los Estados Unidos (Lawrence et al., 2014). Cultivada y escapada de cultivo en las Sierras del Sur de Córdoba.

Obs. Se trata de una especie extremadamente polimorfa, en su hábito, cantidad y forma de los aguijones e indumento, caracteres que pueden variar inclusive en una misma población en distintos años. Tal variación se refleja en la profusa sinonimia que presenta esta especie (cfr. Lawrence et al., 2014).

Material selecto estudiado. ARGENTINA. Prov. Córdoba. Dpto. Colón: El Diquecito, L. Ariza Espinar 315 (12-X-1959) \& 984 (12-X-1960) "A orillas del río" (CORD). Quebrada del Río Primero, A. T. Hunziker 16118 \& 16119 (18-XI1962) \& 16134 (7-XII-1962). "Turiones con hojas 5- y 7-folioladas. Planta ca. 2 m alt. Frutos rojos, morados, sabrosos" (CORD). Dpto. Punilla: Sierra Grande (falda E), Rancho Alegre, detrás del Cerro Blanco, entre ruta 20 y Río Yuspe, ca. 1200 m, A. T. Hunziker 23107, 12-XII-1978 (CORD). Sierra de Achala (falda E): Cuesta de Copina, $2^{\circ}$ puente al subir desde Copina, ca. 1600 m, A. T. Hunziker \& R. Subils 24215, 12-III-1982. "Hojas apenas discoloras, con pústulas de royas. Frutos rojos" (CORD). 


\section{J. J. Cantero et al. - Novedades para la flora de la Argentina}

Rubus phoenicolasius Maxim., Bull. Acad. Imp. Sci. Saint-Pétersbourg 17: 160. 1872. Tipo. JAPÓN. Hakodate, ad lacum Konoma, 3/15 Jul 1861, Maximowicz s.n. (Lectotypus LE 01012799!; isolectotypi: GH 00040701!; K 000737878 !; L 0043352!; LE 01012800, 01013801!, 01013803!, 01013805!; NY 00429708!; P 00755395 !, designado por Grubov, en Buzunova, Novit. Syst. Pl. Vasc. 33: 247. 2001). Fig. 9 C-F.

Arbustos hasta ca. $3 \mathrm{~m}$ alt. Tallos arqueados, densamente pubescentes, con largos pelos no glandulares blanquecinos, delicados, flexuosos, y otros largos y cortos, rojizos, rígidos, erectos, con una cabeza glandular elipsoide caediza; aguijones dispersos, de 4-8 mm long., con ápice recurvado y ancho en la base. Hojas deciduas, 3-(5)-folioladas, con margen anchamente aserrado o doblemente aserrrado, fuertemente discoloras: epifilo verde oscuro, glabrescente y con pelos glandulares en los nervios, hipofilo densamente albo-tomentoso, con nervios rojizo-amarillentos y pelos glandulares y aguijones sobre ellos; pecíolo de 5-6 cm long.; estípulas lineares, hasta de $10 \mathrm{~mm}$ long., con abundantes pelos glandulares rojizos; folíolo terminal anchamente deltado u ovado a suborbicular, de 4-7 x 2-6 cm, base truncada o redondeada o apenas cordada, por lo general trilobado, con peciólulo de 2-2,5 cm long., densamente glandular pubescente y dispersamente armado; folíolos laterales menores, sésiles a subsésiles, base anchamente cuneiforme. Inflorescencias terminales o axilares, 5-30-floras, raquis y pedicelos con abundante pilosidad no glandular y glandular, con aguijones escasos; brácteas ovado-lanceoladas, muy pubescentes, apicalmente trífidas. Bractéolas oval-lanceoladas, enteras, densamente pilosas; flores perfectas, de 6-10 mm diám.; sépalos erectos, lanceolados, ca. 7 x $1 \mathrm{~mm}$ long., largamente acuminados y con ápice recurvo, densamente cubiertos por pelos glandulares y no glandulares; pétalos blanco-lilacinos, obovados a suborbiculares, base largamente unguiculada y pubescente; estambres numerosos, casi tan largos o más cortos que los pétalos; carpelos apenas más largos que los estambres, ovario glabro o pubérulo. Frutos anaranjados, subglobosos, 8-10 mm diám., dulces cuando maduros, drupéolas ca. 40, coherentes pero separándose del receptáculo, lanosas en la base, glabras en el ápice, con superficie reticulado-foveolada.
Distribución y hábitat. Casual. Nativa del este de Asia: China, Japón y Corea (Lu \& Boufford, 2003; Lawrence et al., 2014), introducida en los Estados Unidos, para uso en programas de mejoramiento de las "frambruesas" y como ornamental, es invasora en el este de ese país (Lawrence et al., 2014). En la Argentina, se ha hallado escapada de cultivo solamente en el Valle de Punilla, en márgenes y lecho del curso del Río Cruz Grande, en su parte media y nacientes. Crece preferentemente en el sotobosque.

Obs. Se propaga por rizomas y semillas (Fig. 9 E). Crece formando manchones (Fig. 9 C), entre 5-30 $\mathrm{m}^{2}$ de diámetro merced a su propagación vegetativa. La propagación sexual es facilitada por el agua y consumo de los pájaros. En el hábitat, se han observado poblaciones incipientes a partir de semillas en el lecho del Río Cruz Grande. Posiblemente fue cultivado en viviendas de la periferia y se escapó de su cultivo.

\section{Nombre vulgar. "Zarzamora".}

Uso. Sus frutos son comestibles.

Material estudiado. ARGENTINA. Prov. Córdoba. Dpto. Punilla: Sierra Chica (falda E), Río Grande, L. Volkmann s.n., 15-XII-1995. "N.v.: "Zarzamora". En quebrada, frecuente. Visitada por Sappho sparganura" (CORD 281). Río Cruz Grande, 30 $0^{\circ} 17^{\prime} 02$ 'S, 64 $28^{\prime} 56^{\prime \prime} \mathrm{W}, 1218 \mathrm{~m}, 18$ I-2016, J. J. Cantero 7183 "Frutos anaranjados, comestibles" (CORD).

JAPON. Nippon media, Prov. Senano, [año] 1864, Tschonoski s.n. (GH 00040702; M 0214145; MO-255136; K 000737877; K 000737876; LE 01013806, 01013807, 01013808, 01013809, 01013810 \& 01013811; P 00755320; P 00755321).

\section{Salicaceae}

Populus deltoides W.Bartram ex Marshall, Arbust. Amer. 106. 1785. Tipo. "On banks of large rivers in Carolina and Florida" (Holotypus, n.v.). Fig. 10 A, B.

Populus angulata Aiton, Hort. Kew. [W. Aiton] 3: 407.1789.

Árboles dioicos, caducifolios, hasta de $30 \mathrm{~m}$ alt. Tronco cilíndrico, muy rugoso y alto, corteza 
castaño-grisácea, con grietas longitudinales marcadas, más profundas con la edad; ramas primarias extendidas, largas, formando una amplia copa irregular; ramitas 5-angulares, glabras o algo pilosas. Yemas de invierno verde-amarillentas, glabras o ligeramente pilosas, resinosas (resina amarilla, fragante). Hojas alternas, de 3-14 x
2-12 cm, anchamente triangular-ovadas, base truncada, cordada o anchamente cuneada, márgenes crenado-aserrados, dientes (3-) 5-15 (-30) en cada lado, glándulas basilaminares $0-6$, redondeadas o tubulares; pecíolo aplanado distalmente, de 3-8 cm long. Amentos 15-40-floros, de 8-18 cm long. Flores aperiantadas, imperfectas; las estaminadas

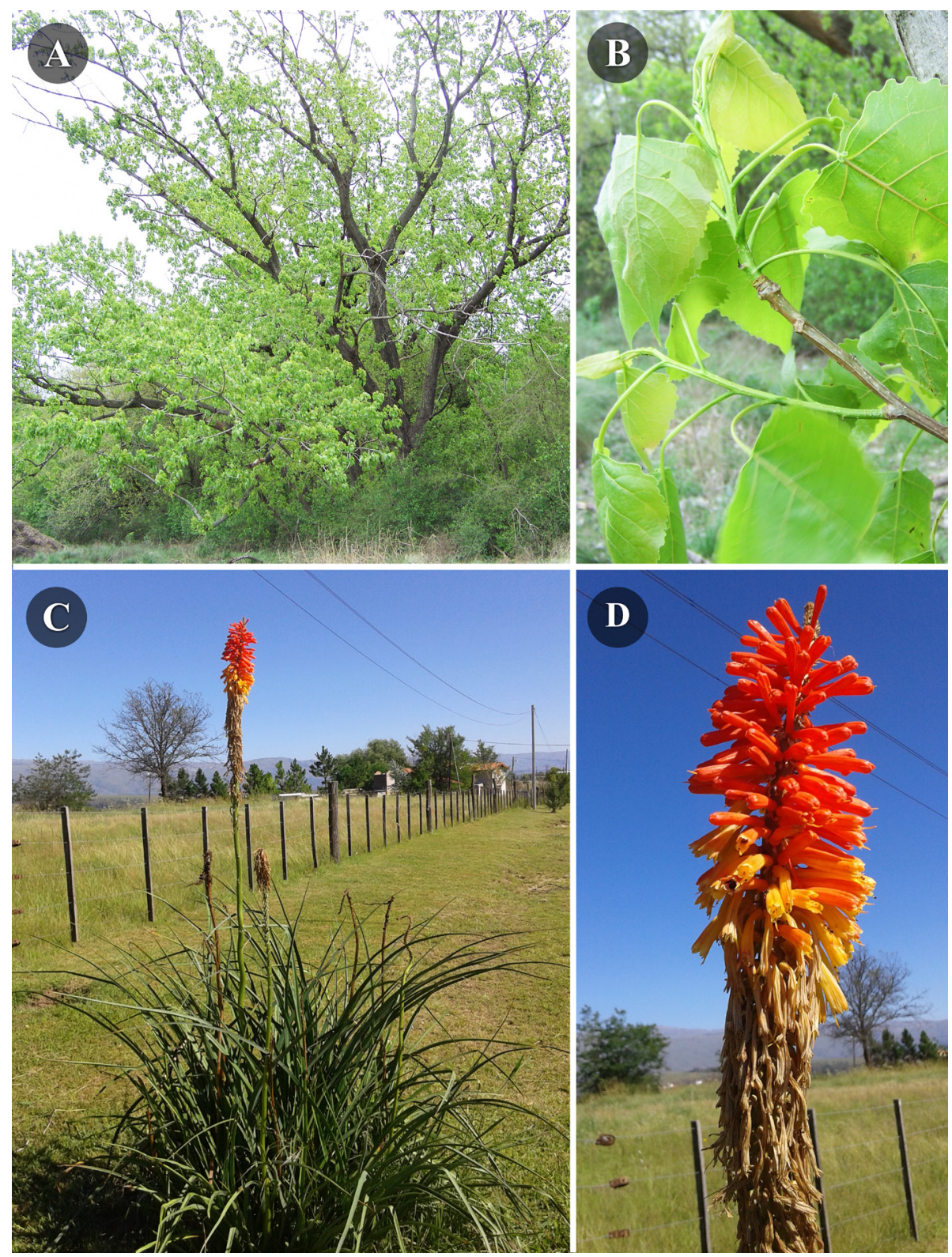

Fig. 10. A, B: Populus deltoides. C, D: Kniphofia uvaria. A, C: Hábito. B: Rama con hojas. D: Inflorescencia. 


\section{J. J. Cantero et al. - Novedades para la flora de la Argentina}

con 30-40 estambres en amentos rojos, gruesos, cilíndrico-cónicos, con las flores protegidas por una escama dentada; flores pistiladas con ovario 3-4-carpelar, ovoide, estigmas 2-4, aplanados. Cápsulas ovoides, de 8-14 mm long., glabras, 3-4-valvares; semillas 7-10 por placenta, lanosas.

Distribución y hábitat. Casual. Nativa de los Estados Unidos y el norte de México (Eckenwalder, 2010). Ampliamente cultivada como forestal y para constituir cortinas protectoras; también como ornamental en el arbolado urbano. En la Argentina, se cultiva y se ha registrado escapada de cultivo en bordes de cursos de agua de las Sierras Chicas del Sur y planicies aluviales del río Cuarto.

Nombres vulgares. “Álamo”, “álamo carolina”.

Material estudiado. ARGENTINA. Prov. Córdoba. Dpto. Punilla, Arroyo Vaquerías, 10X-2015, J. J. Cantero 7177 (CORD). Río Cruz Grande, 30¹7'02'S, 64²8'56”'W, 1218 m, 18-I2016, J. J. Cantero 7191 (CORD) Dpto. Río Cuarto, Campus de la UNRC, márgenes del río Cuarto, 3307'02"S, 64¹8'09'W, 425 m, 9-X-2015, J. J. Cantero 7169 (CORD).

\section{Xanthorrhoeaceae}

Kniphofia uvaria (L.) Oken, Allg. Naturgesch. 3 (1): 566. 1841.

Basónimo: Aloe uvaria L., Sp. Pl. 1: 323. 1753. Tipo: "Habitat ad Cap. B. Spei" (Lectotypus G. Clifford 133, Aloë 14, BM 000558546!, designado por Codd, en Dyer (ed.), Flowering Plants of Africa 33: t. 1289. 1959). Fig. 10 C, D.

Plantas herbáceas, perennes, hasta de 1,5 m alt. Rizomas cortos y raíces fibrosas, carnosas. Hojas lineares, ensiforme-acuminadas, de 50-120 x 1-3 $\mathrm{cm}$, ligeramente glaucas, membranáceas, levemente coriáceas, profundamente acanaladas adaxialmente, margen escabroso, diminutamente dentado en hojas jóvenes. Inflorescencias en racimos simples, densos; brácteas ovadas-obtusas, papiráceas, escapos muy altos. Flores abundantes, erectas al principio y posteriormente péndulas; pedicelos breves, de 1-6 mm long. en floración y 1-1,2 cm long. en fructificación; perianto corolino tubuloso, rojo coral en flores jóvenes, anaranjado, y luego amarillo en flores maduras; estambres exertos a la madurez, anteras oblongas o lineares. Cápsulas loculicidas, ampliamente ovoides, coriáceas; semillas anguladas, negras.

Distribución y hábitat. Casual. Nativa de Sudáfrica (Adamson \& Salter, 1950). En Argentina, ha sido encontrada solo en Córdoba pero es esperable que también se haya dispersado en otras provincias debido a su uso ornamental. Crece escapada de cultivo a orilla de caminos, en localidades de las Sierras Grandes y Chicas.

Obs. Ampliamente utilizada como ornamental (Judd, 1997). Inicialmente descripta como Aloe, se diferencia de las especies de este género por sus hojas membranáceas (vs. hojas suculentas) y sus racimos siempre simples y densos, con pedicelos de 1-6 mm long. en floración (vs. racimos simples o complejos, generalmente laxos, con pedicelos igual o mayores de $6 \mathrm{~mm}$ long. en floración).

Nombres vulgares. "Bandera española", "flor de cohete".

Material estudiado. ARGENTINA. Prov. Córdoba. Dpto. Calamuchita, Yacanto, orilla de ruta Santa Rosa-Yacanto, $100 \mathrm{~m}$ pasando el desvío al Durazno, 3207'10,34'S, 6444'58,84'W, 1165 m, 31-I-2015, R. Deanna 149 (CORD). Dpto. Punilla, entre La Cumbre y Estancia El Rosario, bloque de basalto, 30 $59^{\prime} 02^{\prime}$ 'S, 64²8'32,06"W, 937 m, 5-XII-2014, J. J. Cantero 7031 (CORD).

\section{Documentación de la presencia de especies introducidas}

\section{Cactaceae}

Cylindropuntia imbricata (Haw.) F.M. Knuth

ARGEnTINA. Prov. Córdoba. Dpto. Punilla,

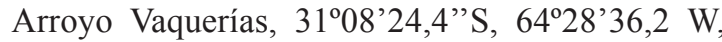
823 m, 9-VI-2015, J. J. Cantero 7142 (CORD).

\section{Cupressaceae}

Hesperocyparis macrocarpa (Hartw. ex Gordon) Bartel (sub Cupressus macrocarpa Hartw. ex Gordon), "ciprés de California", "ciprés de Monterrey".

ARgentina. Prov. Córdoba: Dpto. Punilla, Casa Grande, 3108'38'S, 64²8'57'W, $844 \mathrm{~m}$, 19-V-2015, J. J. Cantero 7085 (CORD). Dique San 
Jerónimo, 3058'79'S, 64²7'52”W, 1283 m, 31V-2015, J. J. Cantero 7131 (CORD).

\section{Fabaceae}

Acacia dealbata Link, "acacia australiana".

ARGEnTINA. Prov. Córdoba: Dpto. Punilla, Camino a Tanti, $31^{\circ} 21^{\prime} 20,55^{\prime}$ 'S, 64³8'01,21'W, 1127 m, 22/7/2015, M. Giorgis 1779 (CORD). Casa Grande, $31^{\circ} 08^{\prime} 38^{\prime} \mathrm{S}, 64^{\circ} 28^{\prime} 57^{\prime} \mathrm{W}, 844 \mathrm{~m}$, 19-V-2015, J. J. Cantero 7084 b (CORD). Dpto. Río Cuarto, Campus Universitario, 33⒉'44", 6432'30", C. Bianco \& J. J. Cantero 2029 (27VIII-1986) \& 2156 (27-VII-1987) (RIOC).

\section{Oenotheraceae}

Oenothera laciniata Hill

ARGENTINA. Prov. Córdoba. Dpto. Río Cuarto, Vicuña McKenna, 12-12-1984, C. Bianco \& Cantero 1756 (CORD, RIOC). Alpa Corral, Pampa de Ortiz, 23-11-1993, J. J. Cantero \& Núñez 4563 (CORD, RIOC). Chaján, campo fiscal, sin fecha, C. Bianco \& Cantero 2005 (CORD, RIOC). Prov. San Luis. Dpto. Pedernera, ruta 148, $25 \mathrm{~km}$ al S de Villa Mercedes. "Bosque de caldén, suelo arenoso", 19-10-1976, D.L. Anderson et al. 3121 (CORD).

\section{Pinaceae}

Pinus elliottii Engelm., "pino".

ARGENTINA. Prov. Córdoba. Dpto. Punilla/ Calamuchita, cercanías de Río La Suela, al lado

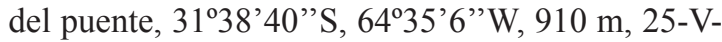
2015, J. J. Cantero 7124 (CORD). Dpto. Río Cuarto, Alpa Corral, cercanías puesto de Tejerina, arriba de la unión de los ríos, 32³8'28"S, 6451'26”'W, 1446 m, 17-X-2015, J. J. Cantero 7181 (CORD).

Pinus halepensis Mill., "pino", "pino de Alepo". ARGENTINA. Prov. Córdoba. Dpto. Punilla, La Cumbre, 3059'32"S, 64³0'16”'W, 10-II-2015, J. J. Cantero 7065 (CORD). Dpto. Río Cuarto, Ambaré, cercanías de Alpa Corral, 32\%41'54"S, 6443'27' 'W, 870 m, 19-V-2015, J. J. Cantero 7100 (CORD).

Pinus patula Schiede ex Schltdl. \& Cham., "pino de las charreteras".

ARGentina. Prov. Córdoba. Dpto. Calamuchita, Villa Alpina, cercanías del pueblo, 31 $57^{\circ} 25^{\prime}$ 'S, 644' 37'W, 1254 m, 25-V-2015, J. J. Cantero 7116 (CORD). Entre la Cumbrecita y
Villa Gral. Belgrano, 31054'27'S, 6444'51'W, 1342 m, 19-V-2015, J. J. Cantero 7113 (CORD). Cerca de Villa Berna, 3154'36"S, 6442'36"W, 1231 m, 16-VIII-2015, M. Giorgis 1786 (CORD).

\section{Rosaceae}

Cotoneaster glaucophyllus Franch., "cotoneaster", "cotoneaster gris".

ARGENTINA. Prov. Córdoba. Dpto. Calamuchita, Villa Alpina, 31 $57^{\circ} 25^{\prime}$ 'S, 644ㅇ'37'W, 1254 m, 25-V-2015, J. J. Cantero 7115. "Crece abundantemente en espacios abiertos dentro del bosque y pastizal serranos" (CORD). Dpto. Punilla, Dique San Jerónimo, 3059'49"S, 64²7'42'W, 1284 m, 31-V-2015, J. J. Cantero 7128 (CORD). Mallín, 3117'53,03”S, 61³4'33,14”W, 957 m, 20-VII-2015, M. Giorgis 1775 (CORD). Dpto. San Alberto, Parque Nacional Quebrada del Condorito, en las márgenes del arroyo El Sauco,

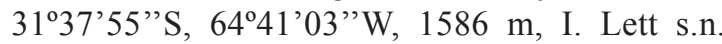
(CORD). Dpto. Santa María, camino Falda del Carmen, 31 35'28,2"S, 64³4'39,1"W, 1020 m, 13-IX-2006, I. Lett s.n. (CORD 1143).

Cotoneaster horizontalis Decne., "cotoneaster rastrero".

ARGEntina. Prov. Córdoba. Dpto. Calamuchita, Cerca de La Cumbrecita, $31^{\circ} 53^{\prime} 20,38^{\prime}, / \quad 31^{\circ} 53^{\prime} 17,34^{\prime}, \mathrm{S}$, 64 $46^{\prime} 22,83^{\prime}{ }^{\circ} / 64^{\circ} 46^{\prime} 23,14^{\prime \prime} \mathrm{W}, 1428-1517 \mathrm{~m}$, 16-VIII-2015, M. Giorgis 1781, 1782 \& 1785 (CORD).

\section{Pyracantha atalantioides (Hance) Stapf}

ARGentina. Prov. Córdoba. Dpto. Calamuchita, Cerca de Los Reartes, 31 54 '54,60"S, 643' $37,11^{\prime}$ 'W, 832 m, 16-VIII-2015, M. Giorgis 1783 \& 1784 (CORD). Dpto. Colón, camino de Ascochinga a La Cumbre, poco antes del acceso a la Estancia San Miguel, 31-I-1997, A. T. Hunziker 25605. "A orillas de arroyito" (CORD). Dpto. Punilla, Dique San Jerónimo, 3059'34”S, 64⒉ $7^{\prime} 70$ "W, 1289 m, 31-V-2015, J. J. Cantero 7125 (CORD). Dpto. Río Cuarto, Alpa Corral, $32^{\circ} 41^{\prime} 49^{\prime \prime} \mathrm{S}, 64^{\circ} 42^{\prime} 34^{\prime \prime} \mathrm{W}, 805 \mathrm{~m}, 19-\mathrm{V}-2015$, J. J. Cantero 7096 (CORD). Dpto. Santa María, La Serranita, 650 m, 12-X-1996, L. Galetto \& C. Torres 412. "Flores blancas, visitadas por una amplia variedad e insectos. Planta ca. $4 \mathrm{~m}$; en ladera de la montaña" (CORD). 


\section{J. J. Cantero et al. - Novedades para la flora de la Argentina}

\section{AGRADECIMIENTOS}

Los autores desean expresar su gratitud a L. Holm-Nielsen (University of the Chinese Academy of Sciences, Beijing), I. Illarionova (LE), R. Klopper (South African National Biodiversity Institute, Pretoria, South Africa) y H. Glen (National Botanical Institute, Pretoria, South Africa) por brindarnos información sobre la identidad, tipos nomenclaturales, bibliografía e imágenes digitales provistas para algunas de las especies de este trabajo; al Dr. A. Fleischmann (Botanische Staatssammlung München) por permitirnos reproducir el lectotipo seleccionado de Rubus erythrocladus; a los Curadores de los herbarios consultados por poner a nuestra disposición el material solicitado; a I. Lett por proveernos colecciones particulares de Cotoneaster y fotografías; a los revisores del manuscrito por las valiosas sugerencias recibidas; a las instituciones que financiaron este estudio, MINCyT-Córdoba, y Secretaría de Ciencia y Tecnología de la Universidad Nacional de Córdoba y de la Universidad Nacional de Río Cuarto.

\section{Biblografía}

ADAMSON, R. S. \& T. M. SALTER. 1950. Flora of the Cape Peninsula. Juta \& Co., Cape Town \& Johannesburg.

ARANA, M. D. \& A. OGGERO. 2009. Zanthoxylum armatum (Rutaceae), su presencia en Argentina. Darwiniana 47: 335-338.

ARANA, M. D., A. J. OGGERO, C. A. BIANCO, G. F. SMITH \& E. FIGUEIREDO. 2012. Aloe maculata (Xanthorrhoeaceae), primer registro para la Flora Argentina. Darwiniana 50: 148-153.

BALABUSIC, A., C. CICHERO \& F. MENVIELLE. 1994. Plan de manejo preliminar del Parque Nacional El Palmar. Fucema, Sarem, AOP y APN, Buenos Aires.

BLANCA, G. \& C. DÍAZ DE LA GUARDIA. 1998. Prunus. In: CASTROVIEJO, S. (coord.), Flora iberica 6, pp. 444-466. Real Jardín Botánico, CSIC, Madrid.

BUSSO, C.A., D. BENTIVEGNA\& O.A. FERNÁNDEZ. 2013. A review on invasive plants in rangelands of Argentina. Interciencia 38: 95-103.

BYWATER, M. \& G. E. WICKENS. 1984. New World species of the genus Crassula. Kew Bull. 39: 699728.

CATALAN, P. 1993. Ficus. In: CASTROVIEJO, S. et al. (eds.). Flora iberica 3, pp. 252. Real Jardín Botánico, CSIC, Madrid.

CHANG, M., L. CHIU, Z. WEI \& P. S. GREEN. 1996. Oleaceae. In: WU, Z. Y. \& P. H. RAVEN (eds.), Flora of China 15, pp. 272-319. Science Press and Missouri Botanical Garden Press, Beijing and St. Louis.

CHIPPENDALE, G. M. 1988. Eucalyptus. In: GEORGE, A. S. (ed.), Flora of Australia (MyrtaceaeEucalyptus, Angophora) 19, pp. 1-448. Australian Government Publishing Service Canberra, Canberra.

CRESPO, M. B. 2013. Iris. In: CASTROVIEJO, S. (coord.). Flora iberica 20, pp. 406-415. Real Jardín Botánico, CSIC, Madrid.

COZZO, D. 1994. Conversión de plantaciones forestales de especies exóticas en sistemas sostenibles en Argentina. Invest. Agrar. Sist. Recur. For. 3: 31-42.

CUEVAS, Y. A. \& S. M. ZALBA. 2009. Control de pinos invasores en el Parque Provincial Ernesto Tornquist (Buenos Aires): áreas prioritarias y análisis de costos. BioScriba 2: 76-89.

CUEVAS, Y. A. \& S. M. ZALBA. 2010. Recovery of native grasslands after removing invasive pines. Restor. Ecol. 18: 711-719.

CUEVAS, Y. A. \& S. M. ZALBA. 2013. Efecto del tipo de corte y de tratamientos en el mantillo para la restauración de pastizales naturales invadidos por Pinus halepensis. Bol. Soc. Argent. Bot. 48: 315-329.

DAVIS, A. \& S. JURY. 1990. A taxonomic review of Iris L. series Unguiculares (Diels) Lawrence. Bot. J. Linn. Soc. 103: 281-300.

DELUCCHI, G. 1996. Especies adventicias nuevas o críticas en la Argentina. Parodiana 9: 115-124.

DELUCCHI, G. 1999. Sobre la presencia de Iris orientalis (Iridaceae) adventicio en la Argentina. Hickenia 3: 51-53.

DELUCCHI, G. 2003. Las especies adventicias del género Allium (Alliaceae) en la Argentina. Bol. Soc. Argent. Bot. 38: 329-335.

DELUCCHI, G. \& J. A. HURRELL. 2011. Taxodium distichum (Cupressaceae) adventicia en la Argentina y Uruguay. Bol. Soc. Argent. Bot. 46: 361-367.

DELUCCHI, G., F. BUET COSTANTINO \& E. L. GUERRERO. 2011. Leguminosas adventicias de la República Argentina. Una categorización. Hist. Nat., $3^{\circ}$ Ser., 1 (2): 75-84.

DIMITRI, M. J. (dir.). 1987. Enciclopedia Argentina de Agricultura y Jardinería, $3^{\mathrm{a}}$ ed. Tomo 1, vol. 1-2. Editorial Acme, Buenos Aires.

ECKENWALDER, J. E. 2010. Populus. In: Flora of North America Editorial Committee (eds.), Flora of North America North of Mexico, vol. 7, pp. 5-22. Oxford University Press, New York and Oxford.

FERRERAS, A. E., G. FUNES \& L. GALETTO. 2014. Evaluación interanual de las estrategias regenerativas 
de la especie exótica invasora Gleditsia triacanthos en relación a la nativa Acacia aroma en el bosque chaqueño serrano de Córdoba (Argentina) Bosque 35: 155-162.

FONSECA, C. R., GUADAGNIN, D. L., EMER, C., MASCIADRI, S., GERMAIN, P. \& S. M. ZALBA. 2013. Invasive alien plants in Pampas grasslands: a tri-national cooperation challenge. Biol. Invas. 15: 1751-1763.

GARCÍA-MENDOZA, A. J. 1987. Monografía del género Beschorneria Kunth (Agavaceae). Tesis de Maestría. Facultad de Ciencias, Universidad Nacional Autónoma de México, México.

GIORGIS, M. A., A. M. CINGOLANI, F. CHIARINI, J. CHIAPELLA, G. E. BARBOZA, L. ARIZA ESPINAR, R. MORERO, D. E. GURVICH, P. TECCO, R. SUBILS \& M. CABIDO. 2011a. Composición florística del Bosque Chaqueño Serrano de la provincia de Córdoba, Argentina. Kurtziana 36: 9-43.

GIORGIS, M. A. \& P. A. TECCO. 2014. Árboles y arbustos invasores de la provincia de Córdoba (Argentina): una contribución a la sistematización de bases de datos globales. Kurtziana 49: 581-603.

GIORGIS, M. A., P. TECCO, A. M. CINGOLANI, P. MARCORA, D. RENISON \& V. PAIARO. 2011b. Factors associated with woody alien species distribution in a newly invaded mountain system of central Argentina. Biol. Invas. 13: 1423-1434.

HAYNES, R. R. \& L. B. HOLM-NIELSEN. 1994. The Alismataceae, Flora Neotropica 64: 1-112. The New York Botanical Garden, New York.

HILL, K. D. 1991. Eucalyptus. In: HARDEN, G. J. (ed.), Flora of New South Wales 2, pp. 76-142. New South Whales University Press, Sydney.

HURRELL, J. A. \& G. DELUCCHI. 2007 a. Agapanthaceae, Anthericaceae y Hyacinthaceae (Monocotyledoneae-Asparagales) adventicias en la Argentina. Revista Mus. Argent. Cienc. Nat., n.s. 9: 103-107.

HURRELL, J. A. \& G. DELUCCHI. $2007 \mathrm{~b}$. Amaryllidaceae adventicias en la Argentina. Bol. Soc. Argent. Bot. 42: 313 - 319.

HURRELL, J.A., D. BAZZANO \& G. DELUCCHI. 2005. Monocotiledóneas Herbáceas. Nativas y exóticas. In: HURRELL, J. A. (ed.), Biota Rioplatense 10, pp. 1-320. Editorial LOLA, Buenos Aires.

HURRELL, J. A., G. DELUCCHI \& F. BUET CONSTANTINO. 2009. Nuevas citas de Monocotiledóneas adventicias para la Argentina. Revista Mus. Argent. Ci. Nat. (n.s.) 11: 131-144.

HURRELl, J. A., G. DELUCCHI, H. A. KELLER, P. C. STAMPELLA \& E. L. GUERRERO. 2012. Bryophyllum (Crassulaceae): especies ornamentales naturalizadas en la Argentina. Bonplandia 21: 169-181.
HURRELL, J. A., G. DELUCCHI \& J. A. TOLABA. 2010. Presencia de Lilium longiflorum (Liliaceae) adventicia en la Argentina. Bol. Soc. Argent. Bot. 45: 195-200.

JUDD, W. S. 1997. The Asphodelaceae in the southeastern United States. Harvard Pap. Bot.: 109-123.

LAWRENCE A. A., D. H. GOLDMAN, J. A. MACKLIN \& G. MOORE. 2014. Rubus. In: Flora of North America Editorial Committee (eds.), Flora of North America North of Mexico, vol. 9. Magnoliophyta: Picramniaceae to Rosaceae, Oxford University Press, New York, Oxford.

LEHTONEN, S. 2008. An integrative approach to species delimitation in Echinodorus (Alismataceae) and the description of two new species. Kew Bull. 63: 525-563.

LEUENBERGER, B. E. \& S. ARROYOLEUENBERGER. 2014. Northern hemisphere Opuntia and Cylindropuntia species (Cactaceae) naturalized in Argentina- and the riddle of Opuntia penicilligera. In: HUNT, D. (ed.). Further studies in the Opuntioideae (Cactaceae). Succ. Pl. Res. 8, pp. 95-118.

LINGDI, L. \& A. BRACH. 2003. Cotoneaster. In: WU, C. Y., P. H. RAVEN \& D. Y. HONG (eds.), Flora of China 9, pp. 85-108. Science Press \& Missouri Botanical Garden Press, Beijing and St. Louis.

LU, L. \& D. E. BOUFFORD. 2003. Rubus L. In Wu, Z. Y., P. H. Raven \& D. Y. Hong (eds.), Flora of China 9, pp. 195-285. Science Press and Missouri Botanical Garden Press, Beijing and St. Louis.

MANGIERI, H. R. \& M. J. DIMITRI. 1961. Los eucaliptos en la silvicultura. Acme, Buenos Aires.

MENDES SILVA, S., S. Y. ABE, F. S. MURAKAMI, G. FRENSCH, F. A. MARQUES \& T. NAKASHIMA. 2011. Essential oils from different plant parts of Eucalyptus cinerea F. Muell. ex Benth. (Myrtaceae) as a source of 1,8-cineole and their bioactivities. Pharmaceuticals (Basel) 4: 1535-1550.

MORICHETTI, S., J. J. CANTERO, C. NÚÑEZ, G. E. BARBOZA, L. ARIZA ESPINAR, A. AMUCHASTEGUI \& J. FERRELL. 2013. Sobre la presencia de Amaranthus palmeri (Amaranthaceae) en Argentina. Bol. Soc. Argent. Bot. 48: 347-354.

NATALE, E. S., J. GASKIN, M. ZALBA, M. CEBALLOS \& H. E. REINOSO. 2008. Especies del género Tamarix (Tamaricaceae) invadiendo ambientes naturales y seminaturales en Argentina. Bol. Soc. Argent. Bot. 43: 137 - 145.

NIEVAS, R. P. \& M. M. MOGLIA. 2013. Flora exótica de una localidad serrana de San Luis (Argentina). Métodos Ecol. Sist. 8: 1-14.

REITZ, R. 1996. Rosáceas. In: REIS, A. (ed.), Fl. Il. Catarinense fasc. ROSA, pp. 5-135. Herbario Barbosa Rodrigues, Itajaí. 


\section{J. J. Cantero et al. - Novedades para la flora de la Argentina}

RICHARDSON, D. M., P. PYŠEK \& J. C. CARLTON. 2011. A compendium of essential concepts and terminology in biological invasions. In: RICHARDSON, D. M. (ed.), Fifty years of invasion ecology: the legacy of Charles Elton, pp. 409-420. Blackwell Publ., Oxford.

SIMÃO-BIANCHINI, R. 2015. Rosaceae. In: Lista de Espécies da Flora do Brasil. Jardim Botânico do Rio de Janeiro. Disponible en: http://floradobrasil. jbrj.gov.br/jabot/floradobrasil/FB32508 [Acesso: 14 Agosto 2015].

SOLBRIG, O. T. 1962. The South American species of Erigeron. Contr. Gray Herb. Harvard Univ. 191: 3-82.

SMITH, G. F., R. R. KLOPPER , E. FIGUEIREDO \& N. R. CROUCH. 2012. Aspects of the taxonomy of Aloe arborescens Mill. (Aphodelaceae: Alooideae). Bradleya 30: 127-137.

TALAVERA, S. 2000. Sophora. In: CASTROVIEJO, S. (coord.), Flora iberica 7 (2), pp. 36. Real Jardín Botánico, CSIC, Madrid.

THIEDE, J. 2001. Agavaceae. In: EGGLI, U. (ed.), Illustrated Handbook of Succulent Plants: Monocotyledons, pp. 5-102. Springer-Verlag, Berlin.

TORRESÍN, J., P. ZAMBONI, W. SIONE, E. RODRÍGUEZ \& P. G. ACEÑOLAZA. 2013. Modelado de la distribución espacial de árboles exóticos invasores (AEI) en el Parque Nacional PreDelta (Entre Ríos, Argentina). Multequina 22: 1-11.

TROIANI, H. O. \& P. STEIBEL. 2008. Reconocimiento de Malezas. Región Subhúmeda y Semiárida Pampeana. Colegio de Ingenieros Agrónomos de La Pampa (CIALP) \& Facultad de Agronomía, Universidad Nacional de La Pampa, Santa Rosa.
TSE-HSIANG, P. \& R. V. KAMELIN. 1996. Plumbaginaceae. In: WU, C. Y., P. H. RAVEN \& D. Y. HONG (eds.), Flora of China 15, pp. 190-204. Science Press \& Missouri Botanical Garden Press, Beijing and St. Louis.

WUNDERLIN, R. P. 1997. Moraceae. In: Flora of North America Editorial Committee (eds.), Flora of North America North of Mexico 3, pp. 388-399. Oxford Univ. Press, New York.

XINQI, CH. \& M. TAMURA. 2000. Ophiopogon. In: WU, Z., P. H. RAVEN \& D. HONG (eds.), Flora of China 24, pp. 252-261. Science Press \& Missouri Botanical Garden Press, Beijing and St. Louis.

ZALBA, S. M. \& C. B. VILLAMIL. 2002. Woody plant invasion in relictual grasslands. Biol. Invas. 4: 55-72.

ZALBA, S. M. \& S. R. ZILLER. 2007. Adaptive management of alien invasive species: putting the theory into practice. Nat. Conser. 5: 86-92.

ZALBA, S. M., Y. A. CUEVAS \& R. M. BÓO. 2008. Invasion of Pinus halepensis Mill. following a wildfire in an Argentine grassland nature reserve. $J$. Environ. Manag. 88: 539-546.

ZALBA, S. M., M. I. SONAGLIONI, C. COMPAGNONI \& C. J. BELENGUER. 2000. Assessing the risk of invasion by an exotic plant in a coastal nature reserve. Biol. Conserv. 93: 203-208.

Recibido el 31 de agosto de 2015, aceptado el 10 de febrero de 2016. 
